\title{
๖Kenyan Long Rains: A Subseasonal Approach to Process-Based Diagnostics
}

\author{
ELLEN DYER ${ }^{\mathrm{a}}$ AND RICHARD WASHINGTON ${ }^{\mathrm{a}}$

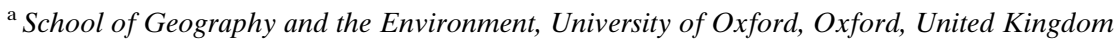

(Manuscript received 7 December 2019, in final form 25 November 2020)

\begin{abstract}
The interannual variability, trends, and the mean climatology of East African long rains are difficult for models to simulate. This is in part because long rains do not respond in a simple way to large-scale modes of variability such as ENSO and because of interactions with complex topography. Here we focus on the Kenyan regional climate in the ERAInterim dataset during the long rains to create a set of atmospheric diagnostics that can be applied to the evaluation of climate models. Subseasonal observed rainfall and reanalysis reveal that very wet seasons and very dry seasons develop differently at the beginning of the season. Subseasonal aggregation periods (days 60-80, 80-100, 90-120, 120-150) highlight local (e.g., midtropospheric ascent, moisture flux convergence in the lower to midtroposphere, and midtropospheric moisture) and large-scale (e.g., midtropospheric zonal winds over central Africa, upper-tropospheric velocity potential) diagnostics that are useful to evaluate model atmospheric circulation affecting Kenyan rainfall in mean and wet or dry extremes.
\end{abstract}

KEYWORDS: Seasonal variability; Africa; Atmospheric circulation; Rainfall; Troposphere; Diagnostics

\section{Introduction}

The ensemble of models in phase 5 of the Coupled Model Intercomparison Project (CMIP5) that forms the modeling basis for the IPCC Fifth Assessment Report (AR5) struggles to simulate projections of future rainfall in East Africa without significant uncertainty (Niang et al. 2014; Tierney et al. 2015). There is also disagreement between GCM representation of the historical climate and observations of the historical climate (Rowell et al. 2015). The problem with model representation of the East African climate is not equally distributed through the annual cycle; models have more difficulty simulating trends in the March-May (MAM) period, or the long-rains season, compared to the October-December (OND) short rains. An improved understanding of the long-rains season is required to be able to evaluate models and to understand changes in future projections of East African climate. To do this, we demonstrate the value in examining East African long rains at a subregional scale and also at a subseasonal scale. Taking this approach, we will create new subseasonal aggregation periods based on how the season evolves, in the mean and extreme composites, and create a set of atmospheric diagnostics that can be used to guide future model evaluations.

The climatology in East Africa is defined by Indian Ocean inflow, accompanied by a strong low-level jet, atmospheric divergence in the midtroposphere, and upper-tropospheric remotely forced descent. The atmosphere in East Africa is therefore not conducive to rainfall. However, during the longrains season there is an increase in low-level moist static energy, driven by moist Indian Ocean inflow (Yang et al. 2015a).

¿ Denotes content that is immediately available upon publication as open access.

Corresponding author: Ellen Dyer, ellen.dyer@ouce.ox.ac.uk
This inflow might also influence the strength of the low-level Turkana jet, which is thought to induce significant lowertropospheric divergence, hindering rainfall (Kinuthia 1992). Zonal winds in the midtroposphere have also been shown to influence the onset of the season, modulating the differential influence of the Atlantic and Indian Oceans (Camberlin and Okoola 2003). Zorita and Tilya (2002) demonstrated the influence meridional winds at the end of the season, highlighting the influence of the Asian monsoon circulation on southerly winds and long-rains cessation. The strength of descent is influenced by large-scale modes of climate variability such as ENSO, but in the mean, the Walker overturning circulation descending branch encompasses the atmosphere over East Africa (Williams and Funk 2011). Teleconnections with largescale modes of variability at the interannual time scale are hard to capture for the long rains, in part because of the East African climate's marginal nature, being located between two convective regions, the Indian Ocean and the Congo Basin, but also because the "spring predictability barrier" coincides broadly with the long rains (Webster and Young 1992). Understanding how the local atmosphere changes through the season in the baseline climatology, and how it is perturbed in seasons that have high or low rainfall may lead to diagnostics of rainfall that are easier to attribute to large-scale structures.

There is already existing motivation for analysis of atmospheric circulation at the subseasonal scale based on the calculation of historical trends, teleconnections (Nicholson 2017), and seasonal predictability and failed rainy seasons (MacLeod 2018). Vellinga and Milton (2018) have also split the long-rains season into March/April and May periods. Rainfall trends in Kenya are, in the regional average, small, and the ability of models to capture the mean climatology of rainfall, and extremes is necessary as in the medium-term variability on the baseline state will most impact on lives and livelihoods. Coupled model biases in the long rains in Kenya are consistently dry in coupled GCM simulations. When the season is 
broken down to the monthly scale, March and April have the largest and most consistent biases but even AMIP simulations have dry biases in April (not shown).

Kenya is actively developing use of its water resources (Hirpa et al. 2018), while many water users still rely on unimproved and variable sources of water with at least one in five people relying on surface sources for drinking water (World Health Organization 2017). This research is part of a water security program the diagnostics of which are designed to be applied to models used for decision making at the national scale (e.g., REACH 2015; https://reachwater.org.uk).

By examining the historical daily mean climatology and perturbations in extreme season rainfall, we will create new subseasonal aggregation periods, and use the associated changes in atmospheric fields to suggest a set of diagnostics with which to understand Kenyan long-rains rainfall. In the process of doing this we will also examine the characteristics of very wet and very dry season rainfall. We go on to briefly examine regional SSTs associated with variability, in part because it has been suggested that atmospheric variables are more useful predictors in forecasts (Nicholson 2017).

We will be highlighting key regional climate processes associated with rainfall onset, peak rainfall and cessation periods as defined by a baseline daily rainfall climatology and wet and dry extremes. We are primarily assessing how conducive atmospheric conditions are to rainfall in this semiarid region, characterized by large-scale subsidence and divergence. Composite analysis, observations, and reanalysis used are described in section 2. Characteristics of baseline, wet, and dry composite rainfall seasons used to determine new subseasonal averaging periods are explored in section 3. Local atmospheric dynamics will then be examined in section 4 by looking at local ascent, moisture convergence and stability in light of the topographically forced flow, and interactions with the coastal Indian Ocean and central Africa. In section 5, interactions with the large-scale overturning circulation are examined with reference to possible SST sensitivities. Finally, a set of diagnostics is discussed along with the implications for future model evaluations.

\section{Composites, observations, and reanalysis}

Separate datasets for rainfall and atmospheric variables are used so that both the rainfall, and atmospheric circulation are being captured as realistically as possible; 1981-2019 is our 39-yr baseline period.

We are use the Climate Hazards Group Infrared Precipitation with Station Data (CHIRPS) merged gauge-satellite dataset (Funk et al. 2015). A benefit of CHIRPS is that it has incorporated many more gauges in East Africa from national meteorological agencies than other rainfall datasets. CHIRPS has been evaluated against other rainfall datasets for East Africa, and at the time scales we will be resampling or smoothing our analysis, CHIRPS is skillful when compared to a local gauge network and other satellite products [African Rainfall Climatology, version 2 (ARC2); Tropical Applications of Meteorology Using Satellite Data and Ground-Based Observations (TAMSAT); Dinku et al. 2018].

For atmospheric variables we use ERA-Interim (Dee et al. 2011), which features in numerous studies of East Africa that focus on large scale, and local interactions, including moisture (Yang et al. 2015b; Vellinga and Milton 2018). We choose ERA-Interim SSTs as we are reaggregating variables, in some cases to periods that are not calendar months and need submonthly time series that are consistent with reanalysis. SST datasets in ERA-Interim change over our baseline period. Before 2002 monthly HadISST and weekly NCEP 2DVAR (from 1982 to 2002) were used, both of which are based on satellite and surface observations (Fiorino 2004). From 2002 the NCEP Real-Time Global Sea Surface Temperature dataset was used (Dee et al. 2011).

To create the wet and dry composite seasons we used daily time series of MAM rainfall. Composites can be chosen in a variety of ways, including rankings as with Vellinga and Milton (2018). Here we choose the wettest and driest 6 years from the 39-yr time series. Wet years were 1981, 1990, 1997, 2010, 2013, and 2018, and dry years were 1983, 1984, 1993, 2000, 2009, and 2011.

Composite significance based on a method described by Boschat et al. (2016) and originally proposed by Terray et al. (2003) that is suitable for small samples is applied to spatial maps and cross sections. In this method, a distribution of composites, with the same number of years as the composite being tested, is created by randomly selecting years. Here we use a random distribution of 1000 with critical thresholds ( $p$ values) at 0.05 and 0.1 , to test whether the composite in question is significantly different from this distribution. The method was created to test significance of composites and can be applied when the sample size is small. Correlations are calculated using Spearman's rank correlation $(r)$ with a twosided $p$ value throughout the study.

\section{Subseasonal rainfall: Baseline mean and composites}

The baseline MAM daily rainfall climatology features the highest rain rates in April with onset and cessation periods in March and May having similar rain rates (Fig. 1). The wet composite has a large increase at the end of March and beginning of April, while May rain rates fall below the climatology in these months. There is some inconsistency in the change between the individual composite years; 1981 is much wetter in March and 1997 is wetter throughout April. Unlike the wet composite, the dry composite departs from the mean climatology from the start until the end of the MAM season. Dry years have a more consistent signature with March and early April being much drier and May having small departures from climatology.

The subseasonal periods highlighted in Fig. 1b (days 60-80, 80-100, 90-120, and 120-150) are the proposed new aggregation periods for decomposition of the MAM season. They are identified qualitatively from the composites of daily rainfall values but are subsequently identified also in atmospheric fields used in this study. April and May are two of these aggregation periods as $50 \%$ of the MAM rainfall occurs during April alone while the wet composite differences are drier in May. May also has some difference in zonal homogeneity. Figure 2 shows a split in the Hovmöller composite differences (Figs. 2c,f) at approximately $39^{\circ} \mathrm{E}$. This is also visible in the 
a) 1981-2016 Baseline and Composite Rainfall

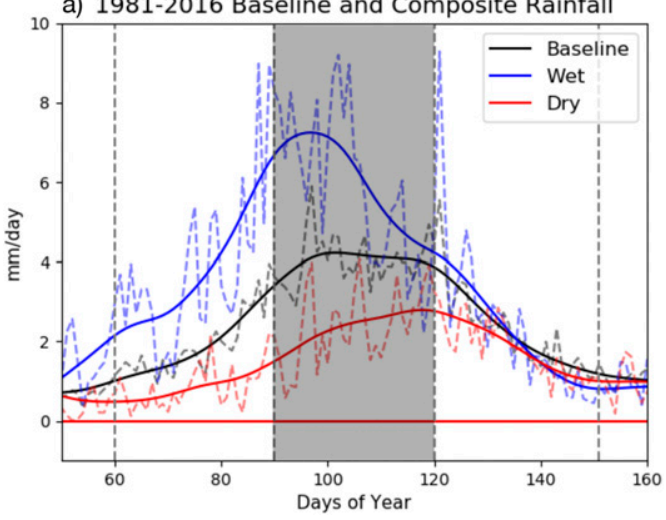

b) Composite Difference Rainfall

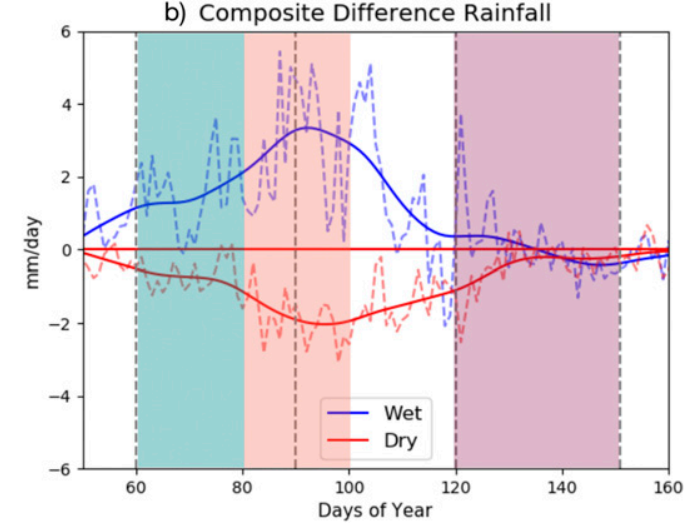

FIG. 1. (a) Daily average baseline climatology of MAM rainfall $\left(\mathrm{mm} \mathrm{day}^{-1}\right)$ averaged from 1981 to 2019 from the CHIRPS dataset masked for Kenya along with wet and dry composite daily climatologies. (b) Daily climatologies of wet and dry composite differences from the baseline daily climatology. Onset rainfall periods are divided into days 60-80 and 80-100, main rainy period days 90-120 (April), and cessation period days 120-150 (May).

mapped May rainfall where coastal wet year rainfall occurs mainly in Ethiopia and Somalia rather than Kenya (Fig. 2e). This is very different from earlier in the season (Figs. 2d,g) when the composite changes are consistent across Kenya, southern Ethiopia and Somalia, and northern Tanzania. The dry composite difference (Fig. 2g) is less spatially consistent, especially across the Turkana channel, northeast Kenya, and Somalia. However, these regions are arid in the baseline so the absolute decrease in dry composites is expected to be small. The end of the season shows much weaker composite changes (Figs. 2e,h) with localized hotspots in the Kenyan highlands and along the coast of the Indian Ocean.

Onset is divided into two 20-day periods of days 60-80 and 80-100 in the new aggregation periods (although the 80-100day period does overlap with the April period). There is some agreement between the timing of greatest composite differences between wet and dry composites; $49 \%$ and $43 \%$ of rainfall change happens during days $80-100$ in wet and dry composites, respectively. For the difference curves in Fig. 2b the half-width at half maximum of the curves occur at days 70-109 for wet composites and days 80-110 for dry composites. Therefore, in choosing the aggregation periods days 60-80, 80-100, and 90-120 we capture the seasonal onset period, the period of greatest perturbation in very wet and dry years, and the period of maximum rainfall in the baseline climatology. This method was chosen as a way of avoiding rainfall thresholds. Days 80-100 in the Hovmöller plots (Figs. 2c and 2f) also show consistent change from the highlands to the coast as shown, with changes later in the season being less spatially consistent.

Composites based on high and low May average rainfall were also calculated (not shown) to see if the difference in signal across Kenya and through the season was consistent. In May based composites there is less zonal asymmetry and less of a clear rainfall change signal earlier in the season, again highlighting the disconnect between the early and late rains in MAM and motivating the final subseasonal period choice of days 120-150.

The CHIRPS and ERA-Interim baseline and composite difference climatologies, using CHIRPS defined composite years, have been compared (not shown) and while ERAInterim has lower baseline rainfall in central Kenya during the wettest part of the rainy season, the composite differences are very similar in zonal extent and in timing. This includes the distinction between March/April and May changes and the zonal confinement of this signal to the coast as shown in Figs. 2c and 2f. Therefore, changes in ERA-Interim atmospheric fields are associated with rainfall changes that are very similar to CHIRPS.

Finally, the composite rainfall changes indicate that significant changes in MAM are more likely to be affected by a shift in the onset date and early season rain rates.

\section{Subseasonal local atmospheric conditions}

\section{a. Local ascent}

The baseline climatology of ascent over Kenya (Fig. 3a), particularly above $700 \mathrm{hPa}$, is the dynamic variable that most closely follows the rainfall climatology. The baseline daily MAM climatology of ascent averaged between 700 and $300 \mathrm{hPa}$ is strongly correlated $(r=0.92, p<0.05)$ with the baseline daily MAM climatology rainfall. Near-surface ascent is strongest at the beginning of the season from day 60 to day 80 before peak rainfall (Fig. 3b). Strong ascent then transitions sharply to much of the depth of the troposphere between 800 and $200 \mathrm{hPa}$, with the lower-level descending anomalies evident from day 80 until the end of May. Upper-level descent weakens between day 120 and day 140. Although low-level ascent is not well timed with rainfall, it may play an important part in setting up the conditions for rainfall in a region dominated by large-scale subsidence and static stability.

During the wettest part in the first half of the season, there is increased ascent above $700 \mathrm{hPa}$ and decreased ascent below this level in the wet composite (Fig. 3c). There is a consistent and opposite change in the dry composite (Fig. 3d). Changes above the $700 \mathrm{hPa}$ level have very similar timing to the rainfall changes (Fig. 1a).

Midtropospheric ascent is clearly associated with increased levels of rainfall, but the low-level strong ascent anomalies at 

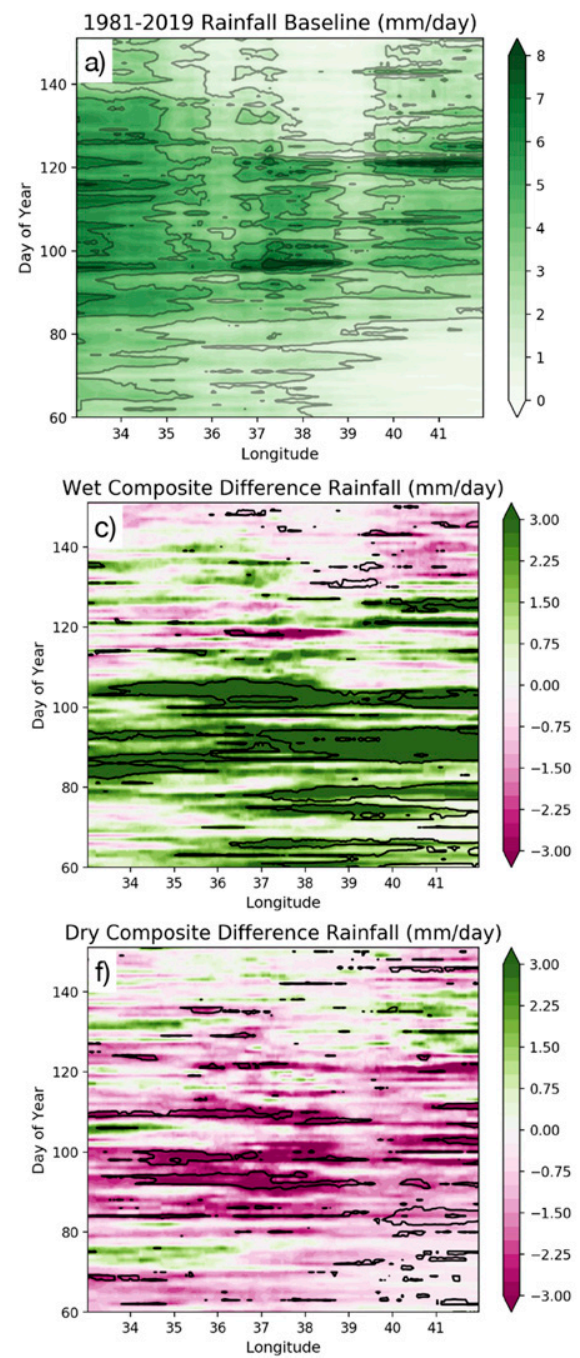

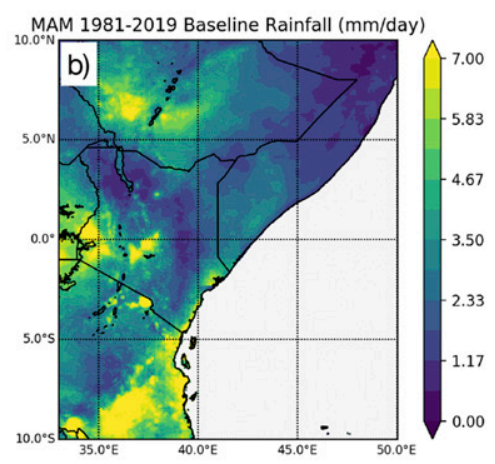

Day 80-100 Wet Composite Difference (mm/day)

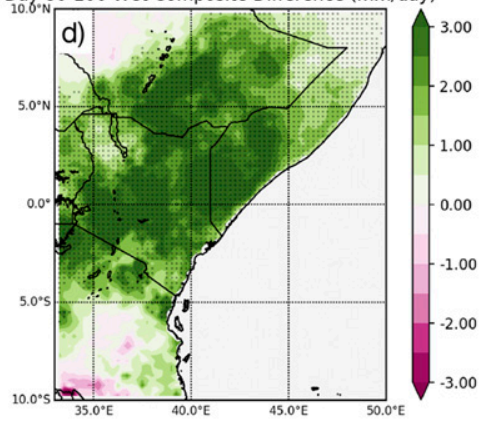

Day 80-100 Dry Composite Difference (mm/day)

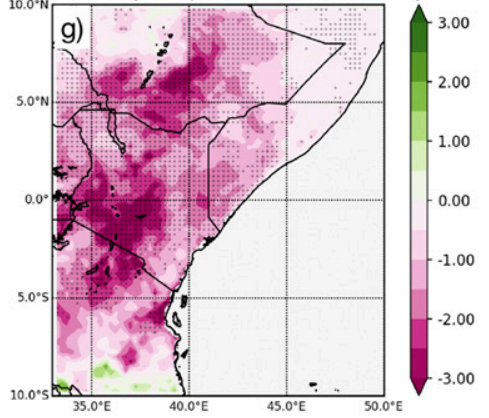

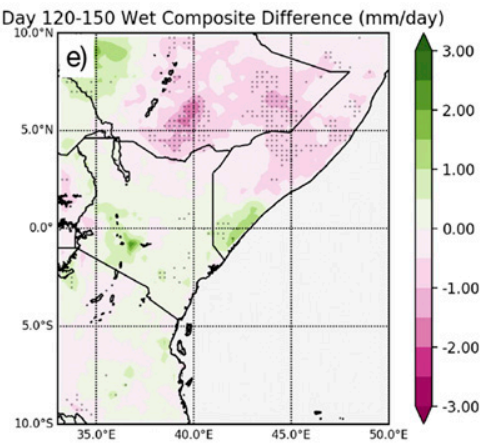

Day 120-150 Dry Composite Difference (mm/day)

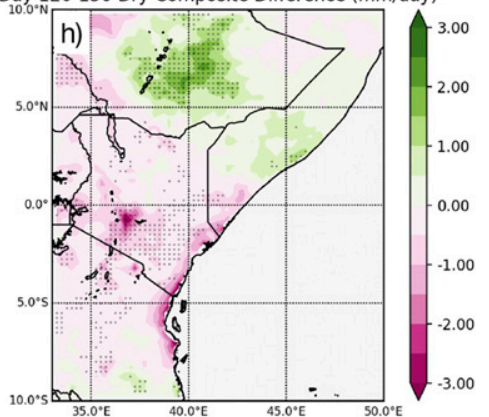

FIG. 2. (a) Daily average Hovmöller of Kenyan MAM rainfall ( $\mathrm{mm} \mathrm{day}^{-1}$ ) averaged from 1981 to 2019 from the CHIRPS dataset and (b) seasonal average map. (c) Wet and (f) dry composite difference rainfall. Hovmöller values are masked for Kenya. Wet composite difference day (d) 80-100 and (e) 120-150 rainfall averages. Dry composite difference day (g) 80-100 and (h) 120-150 rainfall averages. Stippling and black contours indicate composite difference significance of $p<0.05$.

the beginning of the season might either be due to a ventilation mechanism with advection of warm, dry air proposed by Yang et al. (2015a) or due to the effect of surface heating and turbulence in a region with strong externally forced subsidence. The possible influence of ventilation and increased lowertropospheric latent heating is examined more in the following sections (4b, 4c). Strength and depth of mid- to upper-tropospheric ascent is a revealing diagnostic, reflecting somewhat symmetric and consistent changes between composites, but the controls on this circulation and the complex disjointed vertical profile need to be understood in the context of local forcing and large-scale subsidence.

\section{b. Local stability and moisture availability}

Local stability is one way to understand influences on local ascent and associated rainfall. Moist static energy, a useful proxy for potential temperature that is conserved in moist adiabatic motions (Kjellsson 2015), is given by

$$
\mathrm{MSE}=C_{p} T+L_{v} q+g z
$$

where $C_{p}$ is heat capacity of air at constant pressure, $T$ is temperature, $q$ is specific humidity, $L_{v}$ is latent heat of vaporization of liquid water, $g$ is gravity, and $z$ is altitude. Here we divide MSE by $C_{p}$ as in Yang et al. (2015a). Profiles and stratifications of MSE are a good measure of atmospheric stability and potential for rainfall.

In the baseline, shown in Fig. 4a, Kenya is characterized by a MSE profile with a midtropospheric $(700-500 \mathrm{hPa})$ minimum. As the season evolves midtropospheric MSE (Fig. 4b) increases likely in response to convective moistening and heating. The dry static energy (DSE $=C_{p} T+g z$ ) (not shown) features a steep gradient that increases through the troposphere. In the baseline seasonal 

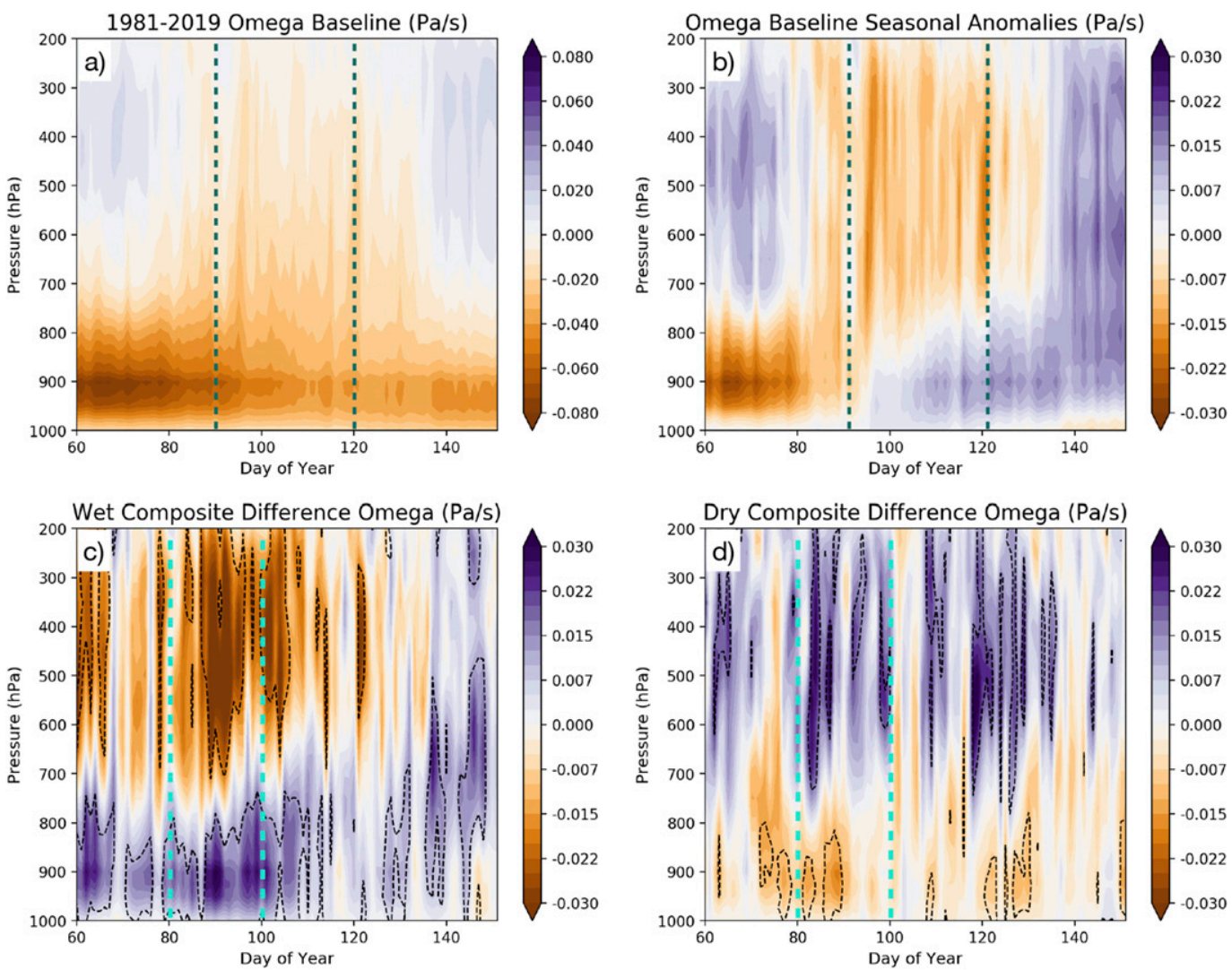

FIG. 3. (a) Daily average climatology ERA-Interim vertical velocity $\left(\mathrm{Pa} \mathrm{s}^{-1}\right.$ ) over Kenya averaged from 1981 to 2019. (b) Daily baseline seasonal anomaly (difference between daily climatology and seasonal average). (c) Wet composite difference (wet - baseline) vertical velocity and (d) dry composite difference vertical velocity. Profiles are averaged over $4^{\circ} \mathrm{S}-4^{\circ} \mathrm{N}, 33^{\circ}-42^{\circ} \mathrm{E}$. Black contours indicate composite difference significance of $p<0.05$.

anomalies from day 60 to day 80 there is an increase in lower-level DSE that precedes the low-level MSE anomaly and aligns with March low-level strong ascent. While the DSE captures the influence of surface heating and vertical advection of heat, the difference between changes in rainfall at the beginning and end of the rainy seasons is best captured in the MSE composite differences. The dominant change is defined by the latent heating component $\left(L_{v} q\right)$, and this indicates that the inflow of tropospheric moisture is the most influential of the MSE terms.

The baseline daily MAM climatology of low-level (1000$925 \mathrm{hPa}$ ) MSE correlation with rainfall in the baseline is 0.87 $(p<0.05)$. The importance of low-level MSE to rainfall seasonality and change is investigated in Fig. 5 through thermal buoyancy. Baseline (Fig. 5a) and composite changes (Figs. 5b,c) in midtropospheric saturated energy and surface MSE are shown along with the resultant thermal buoyancy. We use $700 \mathrm{hPa}$ for the saturated level as in Yang et al. (2015a) who showed that this difference defines the baseline monthly climatology of East African rainfall. The differences in thermal buoyancy are dominated by the near-surface change in MSE. In both composite differences there is a decrease in midtropospheric saturated moist static energy in the onset period, with the change in buoyancy following the perturbations in surface MSE.
Although rainfall seasonality and variability are strongly connected to the thermal buoyancy, the composite differences in the column shown in Figs. $4 \mathrm{c}$ and $4 \mathrm{~d}$ are much larger in the mid- rather than lower-tropospheric change in MSE and there is a significant correlation of daily midtroposphere $(500-700 \mathrm{hPa})$ MSE with rainfall $(r=0.68, p<0.05)$. Since the change in MSE in the midtroposphere is dominated by the change in moisture, there is also plausibly a positive feedback between the amount of free-tropospheric moisture above the boundary layer and rainfall in Kenya. The buoyancy of the low-level parcels changes once lifted due to the entrainment of either dry or moist air (Holloway and Neelin 2009). However, entrainment of moisture does not only happen through vertical motions and the effect of environmental moisture in the free troposphere has been shown to modulate the transition between shallow and deep convection and entrainment of wet/dry air can serve to sustain or dampen convection (Derbyshire et al. 2004; Sherwood 1999). Therefore, while lower-tropospheric moisture influences stability and initiation, moisture higher up in the troposphere may play a role in modulating the intensity and persistence of rainfall in the baseline climatology.

The changes in stability and ascent are associated with a change in the local moisture profile. There is not a large source of atmospheric moisture from local evaporation, with much of 

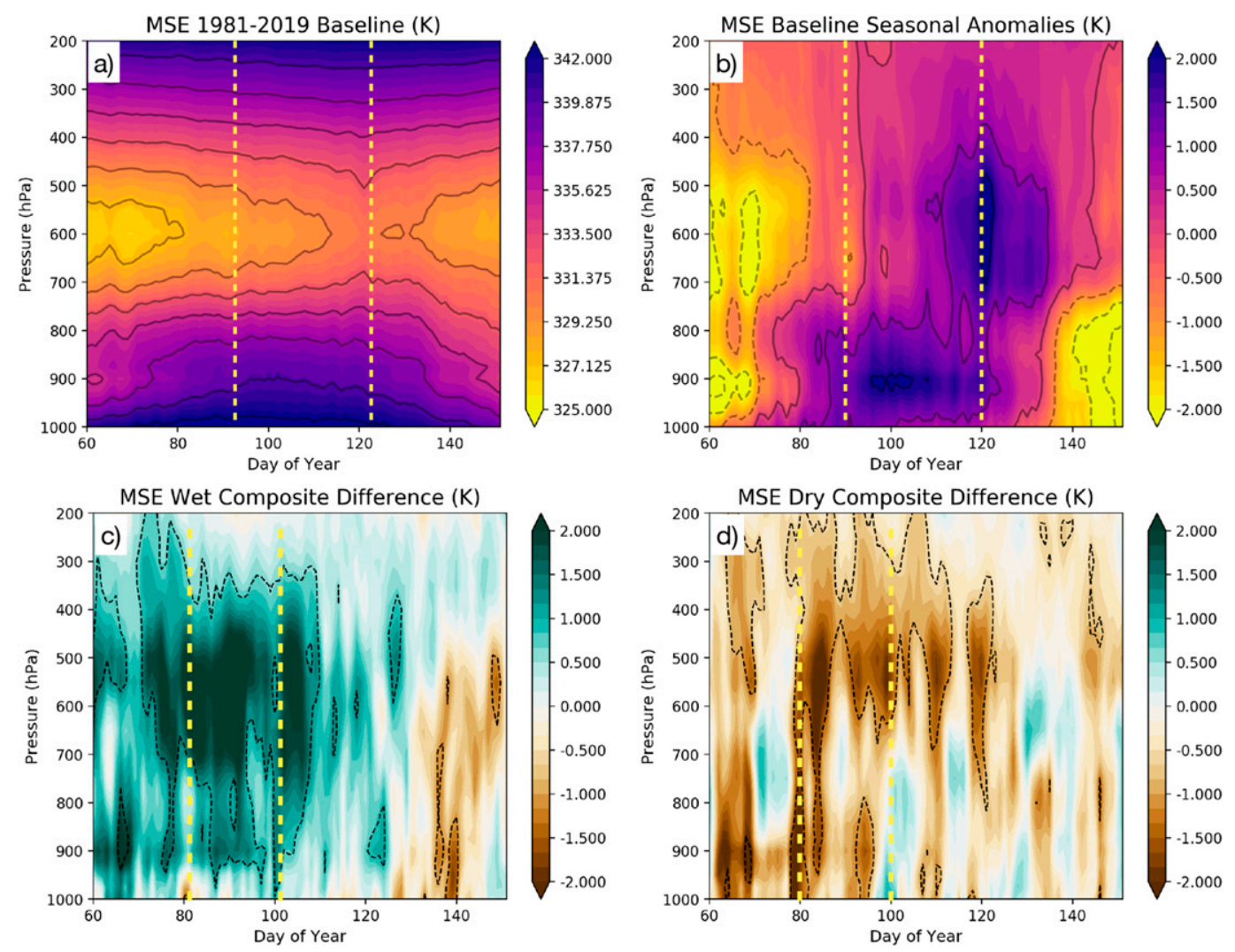

FIG. 4. (a) Daily average climatology ERA-Interim MSE (K) over Kenya averaged from 1981 to 2019. (b) Daily baseline seasonal anomaly (difference between daily climatology and seasonal average). (c) Wet composite difference (wet - baseline) MSE and (d) dry composite difference MSE. Profiles are averaged over $4^{\circ} \mathrm{S}-4^{\circ} \mathrm{N}, 33^{\circ}-$ $42^{\circ}$ E. All values are scaled by $C_{p}$. Black contours indicate composite difference significance of $p<0.05$.

Kenya categorized as arid or semiarid. However, there are regional moisture sources such as the Congo Basin to the west, and the Indian Ocean whose influence depends on advection into the region.

\section{c. Regional moisture flux and convergence}

Understanding the effects of moisture transport and potential moisture sources can be achieved by looking at both moisture flux and convergence (MFC), represented as follows:

$$
\mathrm{MFC}=-\nabla \cdot\left(q \mathbf{V}_{h}\right),
$$

where $q$ is specific humidity, and $\mathbf{V}_{h}$ is the horizontal wind vector. MFC has been used as a dynamic diagnostic for rainfall, and as a model diagnostic that does not depend directly on convective parameterizations (Creese and Washington 2016;
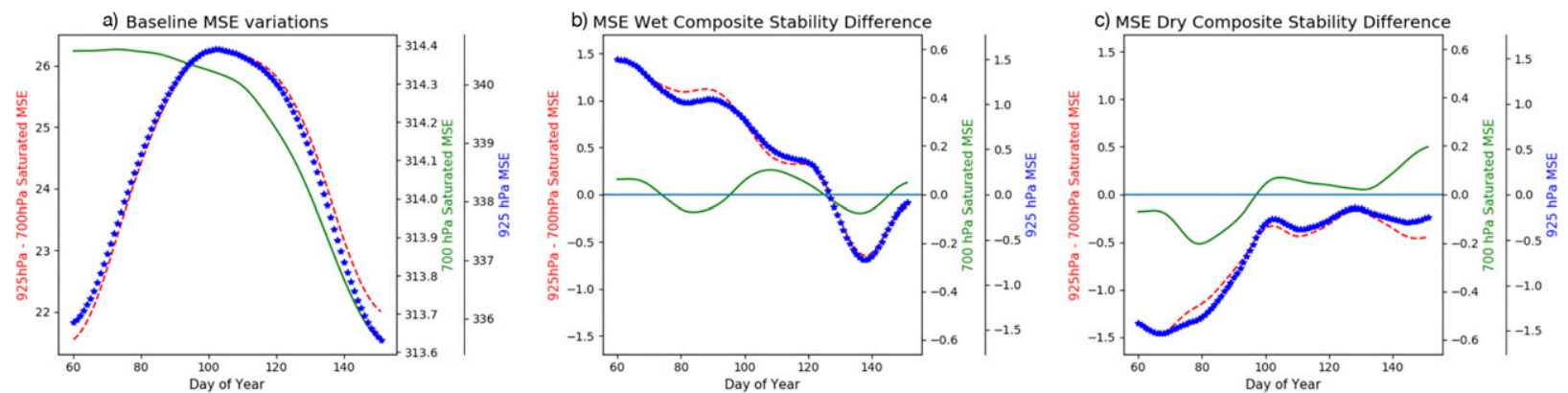

FIG. 5. Seasonal climatologies ERA-Interim $700 \mathrm{hPa}$ saturated MSE (K) (green solid), $925 \mathrm{hPa}$ MSE (blue asterisks), and their difference over Kenya (red dashed) averaged for the 1981-2019 (a) baseline, the (b) wet composite difference, and the (c) dry composite difference. Values are averaged over $4^{\circ} \mathrm{S}-4^{\circ} \mathrm{N}, 33^{\circ}-42^{\circ} \mathrm{E}$ and are scaled by $C_{p}$. 

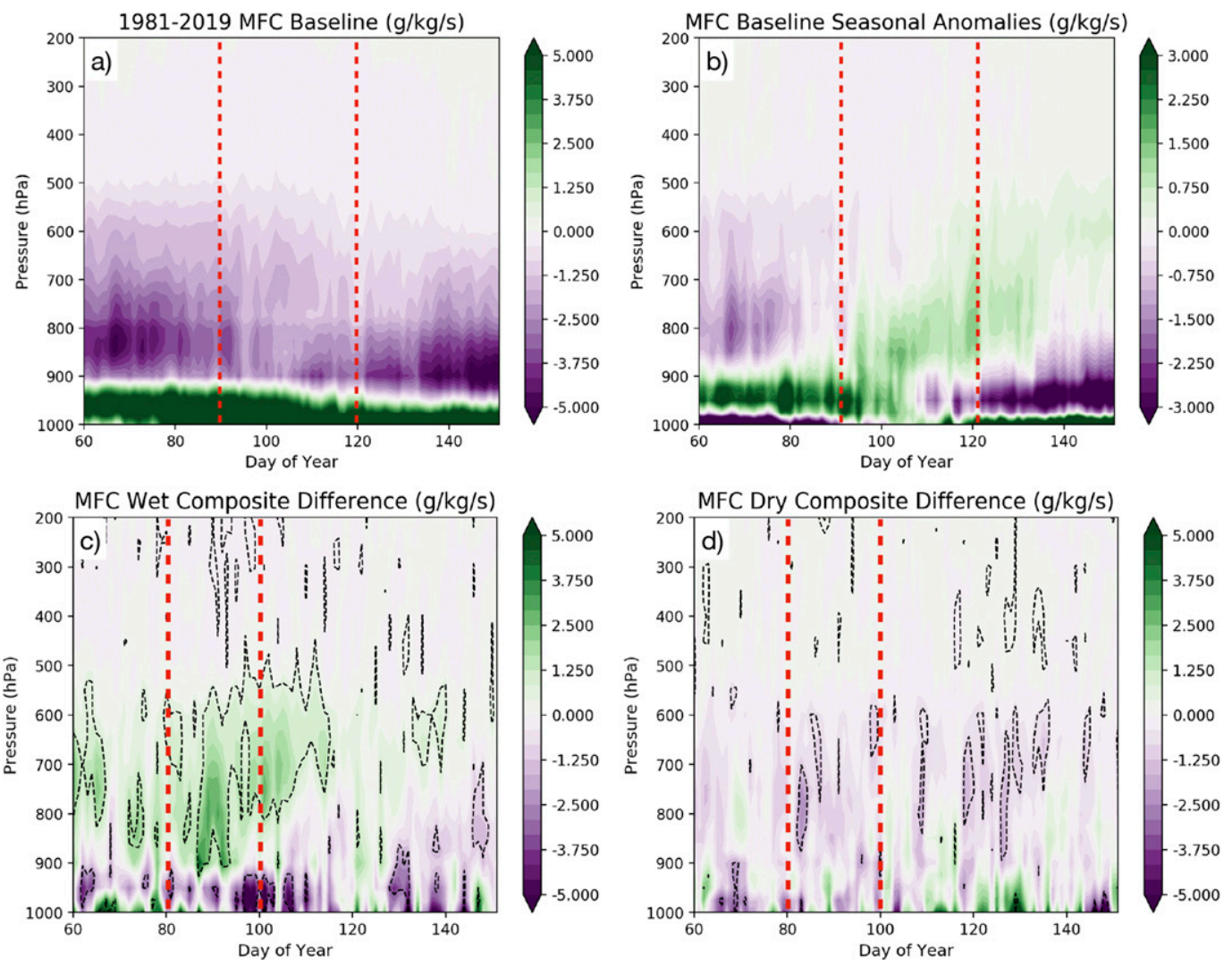

FIG. 6. (a) Daily average climatology of ERA-Interim MFC $\left(\mathrm{g} \mathrm{kg}^{-1} \mathrm{~s}\right)$ over Kenya averaged from 1981 to 2019. (b) Daily baseline seasonal anomaly (difference between daily climatology and seasonal average). (c) Wet composite difference (wet - baseline) MFC and (d) dry composite difference MFC. Profiles are averaged over $4^{\circ} \mathrm{S}-4^{\circ} \mathrm{N}$, $33^{\circ}-42^{\circ} \mathrm{E}$. All values are scaled by $10^{6}$. Black contours indicate composite difference significance of $p<0.05$.

Washington et al. 2013). The baseline of column MFC (Fig. 6a) shows convergence in lowest part of the troposphere (below $900 \mathrm{hPa}$ ). Above this is a layer of divergence that weakens as the rainy season begins, and strengthens again at the end of the season, highlighting the stable state and unfavorable environment for rainfall. Baseline seasonal anomalies in Fig. 6b show that there is a change in the vertical profile of the MFC when rainfall begins, near day 90 , and that the layer of divergence is weakened in the midtroposphere. The variability of the divergent layer $(900-600 \mathrm{hPa})$ does correlate well on the daily scale with rainfall $(r=0.88, p<0.05)$.

Composite differences in the profile (Fig. 6c) are not as consistently timed with rainfall as ascent, although there are contemporaneous changes in the time of the season with the largest changes in rainfall, that is, days 80-100. In wet years there is an increase in midtropospheric convergence at the beginning of the season, accompanied by decreases in low-level convergence. Contrary to the wet composite changes, the dry composite differences are not characterized by a contrast between the mid- and lower troposphere, again highlighting the importance of moisture in the midtroposphere. For the onset period and that with greatest rainfall (days 60-80 and 80-100) we map MFC spatially in the lower troposphere to examine changes in the strongly divergent layer (Figs. 7 and 8), but also the midtroposphere (Fig. 9) to understand what is influencing the bulk of the change in MFC for days 80-100.

There is little difference in the spatial pattern of MFC between days $60-80$ (Fig. $7 b$ ) and 80-100 (Fig. 8b) at $850 \mathrm{hPa}$, the level at which the Turkana jet core tends to be strongest (Nicholson 2016). However, moisture flux does change between these two periods. The day 60-80 average moisture flux into Kenya (Fig. 7a) is northeasterly with a stronger easterly component at the surface; above this level moisture flux is mainly from arid Somalia and eastern Ethiopia (not shown). In the day 80-100 average (Fig. 8a), this has already changed with the addition of moisture flux from the southwest Indian Ocean.

For days 60-80, in wet years (Fig. 7c), the change in moisture flux is an increase in southeasterly inflow and an increase in lowertropospheric moisture north of $5^{\circ} \mathrm{S}$. In dry years (Fig. 7e) there is less moisture, and an increase in the northeasterly flow passing south through Somalia. In wet years there is an increase in moisture along the coast of Somalia with a corresponding increase in northeasterly moisture flux along the coast and into Kenya. This is accompanied by a decrease in easterly wind through the Turkana channel leading to positive change in MFC. The increase in lowlevel moisture inflow corresponds well with the timing of positive buoyancy changes shown in Fig. 5 b.

Wet years in the day-80-100 period (Fig. 8c), show a change in moisture flux primarily through a weakening of the inflow 
a) Mean wind over moisture (1981-2019) $850(\mathrm{hPa})$

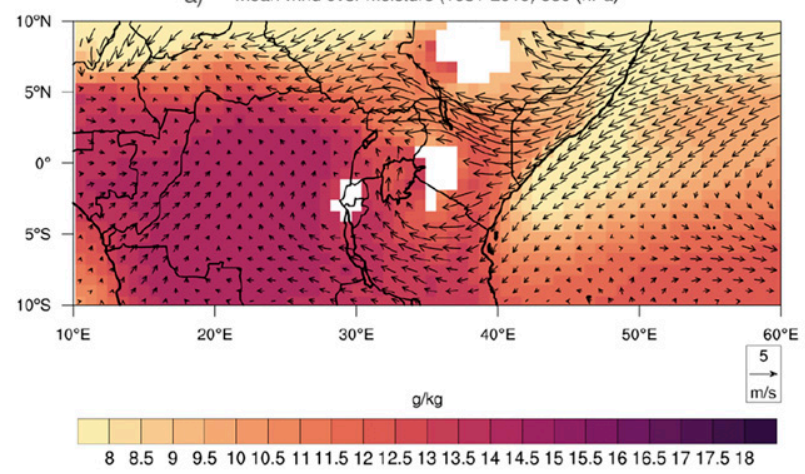

C) Wet difference wind over specific humidity $850(\mathrm{hPa})$

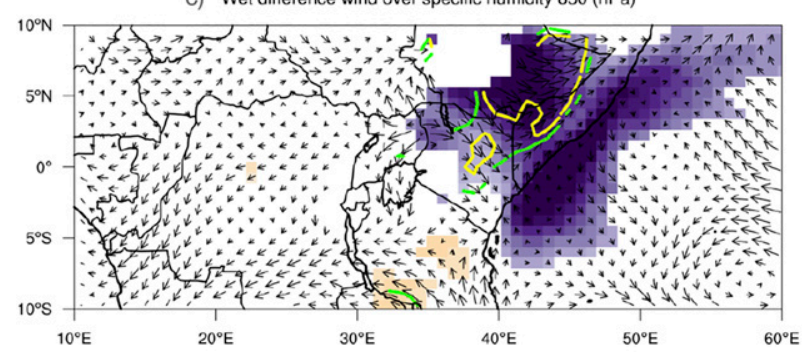

e) Dry difference wind over specific humidity $850(\mathrm{hPa})$

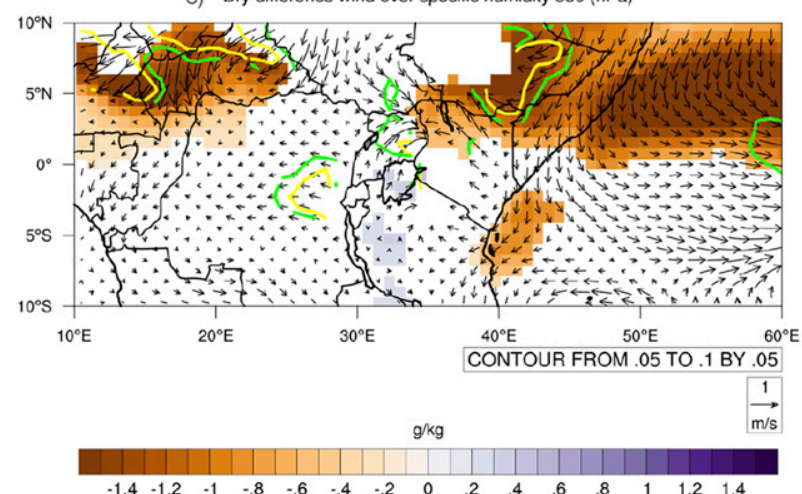

b) Mean moisture flux over MFC (1981-2019) 850 (hPa)

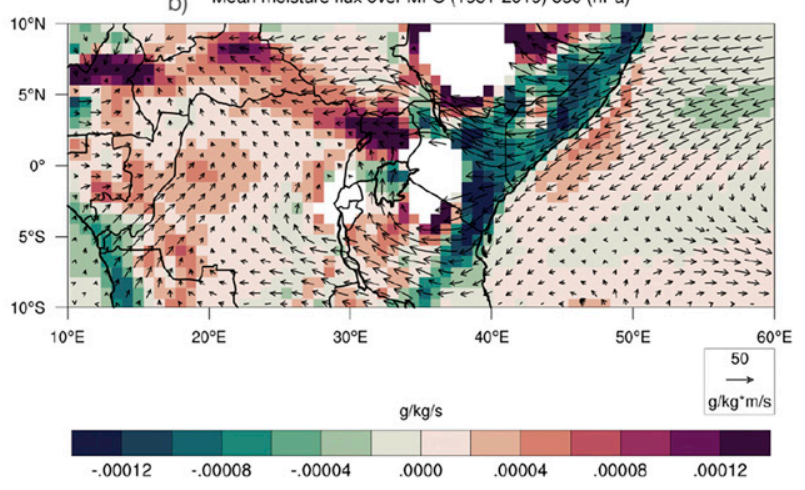

d) Wet difference moisture flux over MFC $850(\mathrm{hPa})$

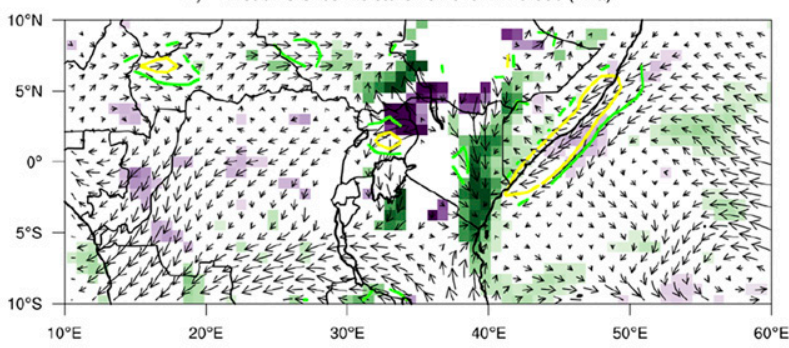

f) Dry difference moisture flux over MFC $850(\mathrm{hPa})$

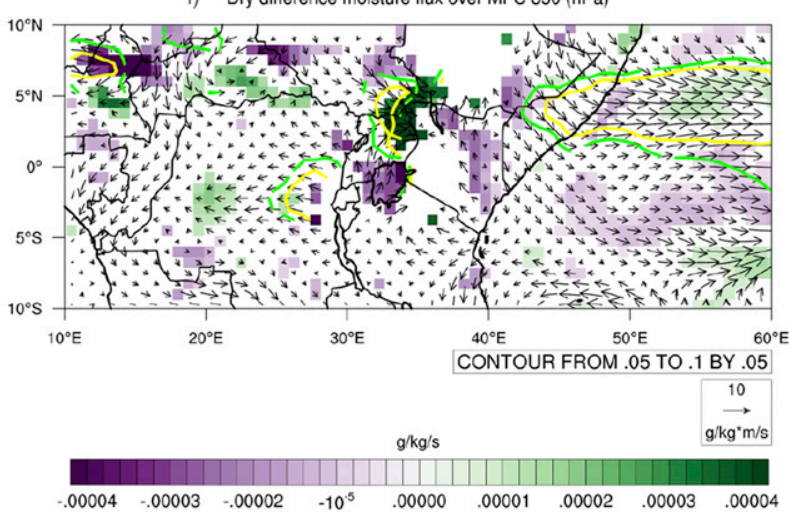

FIG. 7. Day-60-80 $850 \mathrm{hPa}$ averaged ERA-Interim moisture flux and convergence. (a) Baseline winds ( $\mathrm{m} \mathrm{s}^{-1}$ ) over specific humidity $\left(\mathrm{g} \mathrm{kg}^{-1}\right)$ and (b) moisture flux $\left(\mathrm{g} \mathrm{kg}^{-1} \mathrm{~m} \mathrm{~s}^{-1}\right)$ over moisture flux convergence $\left(\mathrm{g} \mathrm{kg} \mathrm{s}^{-1}\right)$. Wet and dry composite differences of (c), (e) winds over moisture and (d),(f) moisture flux over moist flux convergence, respectively. Moisture and moisture flux convergence are masked for $p<0.1$, and green and yellow contours indicate $p=0.1$ and $p=0.05$ for wind and moisture flux vectors, respectively.

into the region and a reduction in the divergence associated with the weakening of the Turkana jet (Fig. 8d). The opposite is true of the dry composite difference (Fig. 8f).

In the midtroposphere at $700 \mathrm{hPa}$ there is a break in the pattern of divergence with the Kenyan highlands being divergent but the Turkana channel and eastern Kenya being weakly convergent (Fig. 9b). Cross continental flow is mostly occurring at $700 \mathrm{hPa}$, and in the baseline is strongest around $2^{\circ} \mathrm{N}$. In wet years there is a westerly anomaly across the Congo Basin that is significant from $8^{\circ} \mathrm{S}$ to $8^{\circ} \mathrm{N}$, while in dry years there is an easterly anomaly significant in a narrower band from $0^{\circ}$ to $8^{\circ} \mathrm{S}$. These flow anomalies are accompanied by changes in MFC (Figs. 9d,f) around the Kenyan highlands and other areas of topography in East Africa; a westerly (easterly) flow anomaly is associated with a convergent (divergent) anomaly. In the day-60-80 period, the $700 \mathrm{hPa}$ wind anomalies (not shown) are reversed and are weak over the Congo and stronger over Kenya. Although it is not concurrent with maximum rainfall change, it may play a role in priming the atmosphere with moisture.

The relationship between Indian Ocean moisture inflow and the dynamic influence on divergent flow through the Turkana channel and highland topography is of clear importance to the Kenyan longrains season, and this is highlighted by the changes in the wet and dry composite years. Additionally, the importance of cross continental flow, changes in which are associated with changes in highland moisture convergence, has been highlighted in the lower midtroposphere where changes in MSE and local ascent are most prominent. 
a) Mean wind over moisture (1981-2019) $850(\mathrm{hPa})$

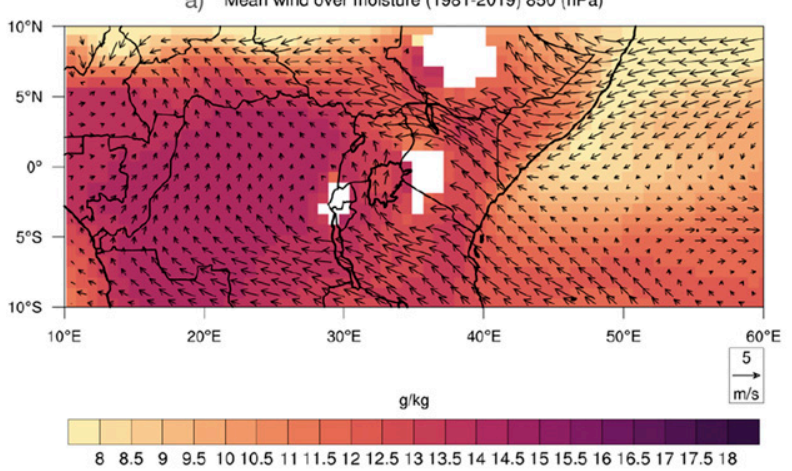

C) Wet difference wind over specific humidity $850(\mathrm{hPa})$

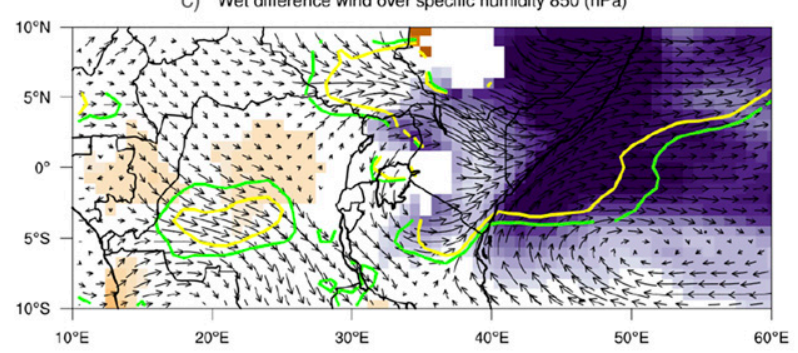

e) Dry difference wind over specific humidity $850(\mathrm{hPa})$

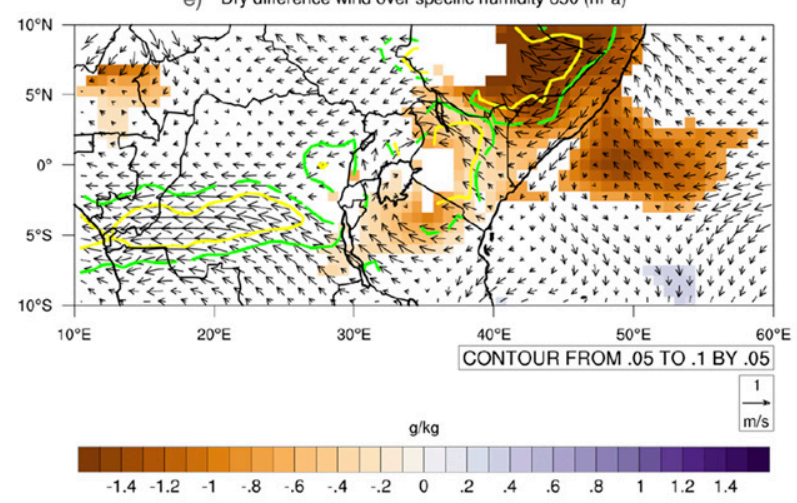

b) Mean moisture flux over MFC (1981-2019) $850(\mathrm{hPa})$

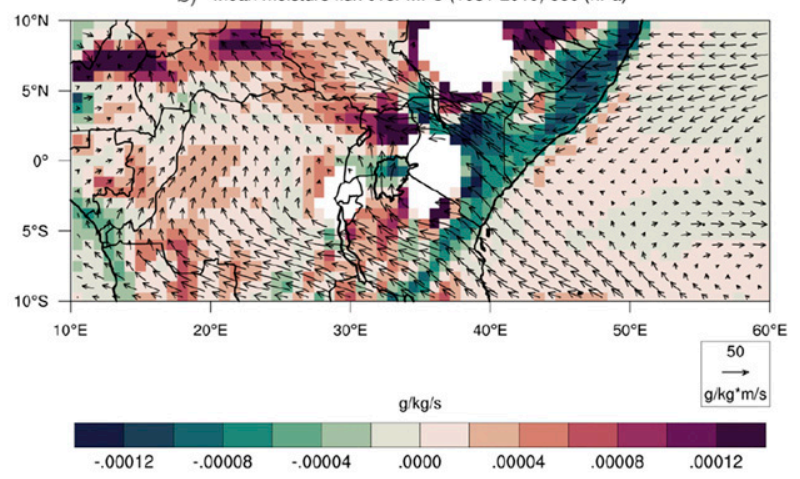

d) Wet difference moisture flux over MFC $850(\mathrm{hPa})$

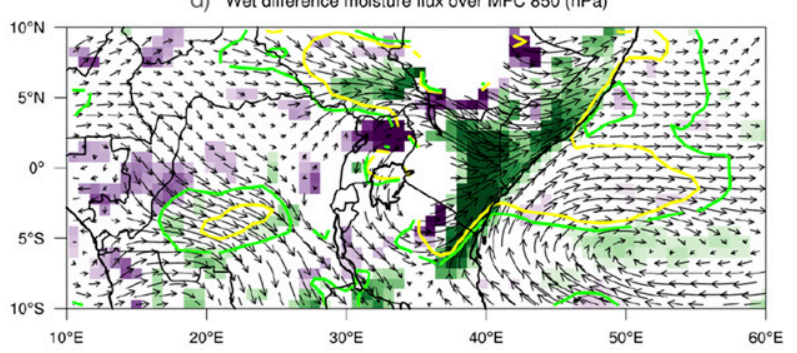

f) Dry difference moisture flux over MFC $850(\mathrm{hPa})$

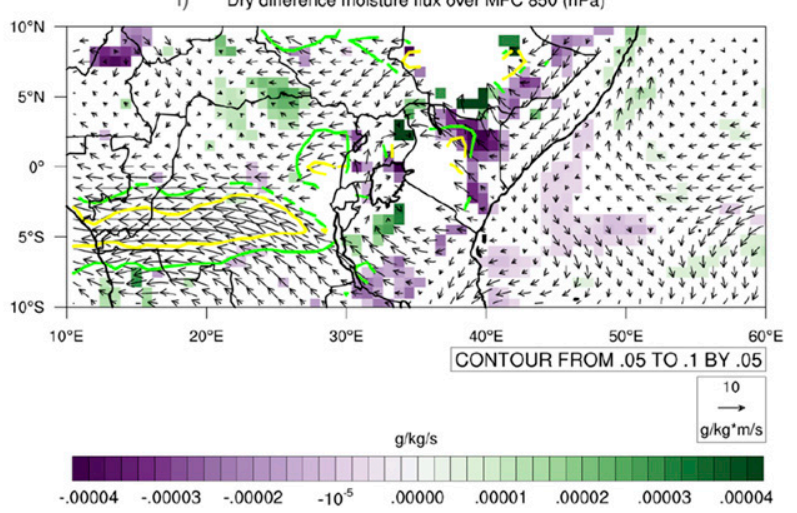

FIG. 8. Day-80-100 $850 \mathrm{hPa}$ averaged moisture flux and convergence. (a) Baseline winds $\left(\mathrm{m} \mathrm{s}^{-1}\right)$ over specific humidity (g kg $\left.{ }^{-1}\right)$ and (b) moisture flux $\left(\mathrm{g} \mathrm{kg} \mathrm{m} \mathrm{s}^{-1}\right.$ ) over moisture flux convergence ( $\mathrm{g} \mathrm{kg} \mathrm{s}$ ). Wet and dry composite differences of (c), (e) winds over moisture and (d),(f) moisture flux over moist flux convergence, respectively. Moisture and moisture flux convergence are masked for $p<0.1$, and green and yellow contours indicate $p=0.1$ and $p=0.05$ for wind and moisture flux vectors, respectively.

\section{Large-scale atmospheric circulation and SSTs}

Changes in regional circulation including midtropospheric equatorial easterlies are set within the context of the large-scale overturning circulations. Upper-tropospheric velocity potential $\chi$ is a proxy for large-scale ascent and descent and is calculated from the following relationship with divergence $(D)$ using $200 \mathrm{hPa}$ horizontal winds $\left(\mathbf{V}_{h}\right)$ and is a smoothed potential field with divergent wind flowing from regions of high to low velocity potential:

$$
D=\nabla \cdot \mathbf{V}_{h}=-\nabla^{2} \chi
$$

Here we use the windspharm spherical harmonics library to calculate the global velocity potential (Dawson 2016).
The baseline climatology of subseasonal velocity potential aggregates is shown in Fig. 10. At the start of the long-rains season there is strong ascent over the Maritime Continent and the western Pacific warm pool, accompanied by descent over Africa, the Atlantic, and the eastern Pacific, with the strongest descent north of the equator. As the season progresses, there is a latitudinal shift in this pattern, with the strongest ascent predominantly north of the equator and strongest descent in southern Africa. This latitudinal shift in velocity potential is partly determined by the Hadley and monsoonal component of the overturning, including the development of the Asian monsoon circulation (Tanaka et al. 2004).

Throughout the season, Kenya is on the margin of regions of strong descent and in the mean, the period of highest MAM rain rates is when there is a weakening of large-scale descent, 
a) Mean wind over moisture (1981-2019) $700(\mathrm{hPa})$

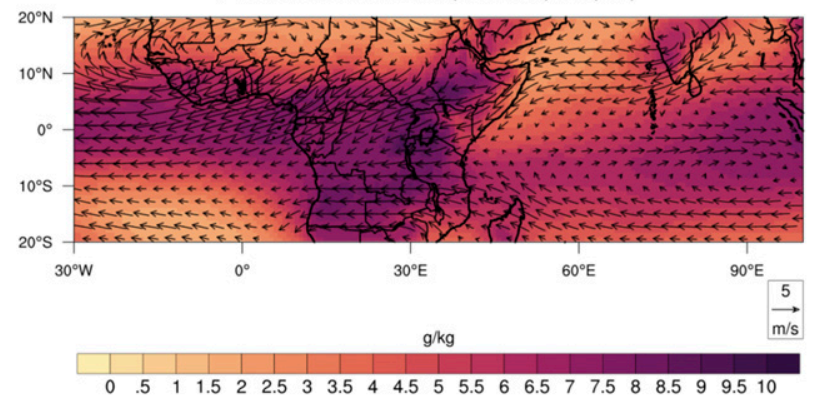

C) Wet difference wind over specific humidity $700(\mathrm{hPa})$

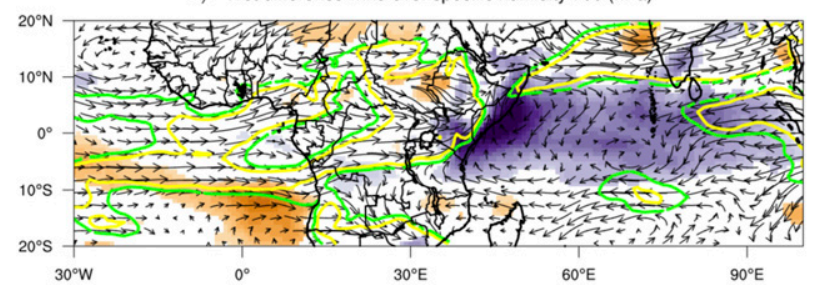

e) Dry difference wind over specific humidity $700(\mathrm{hPa})$

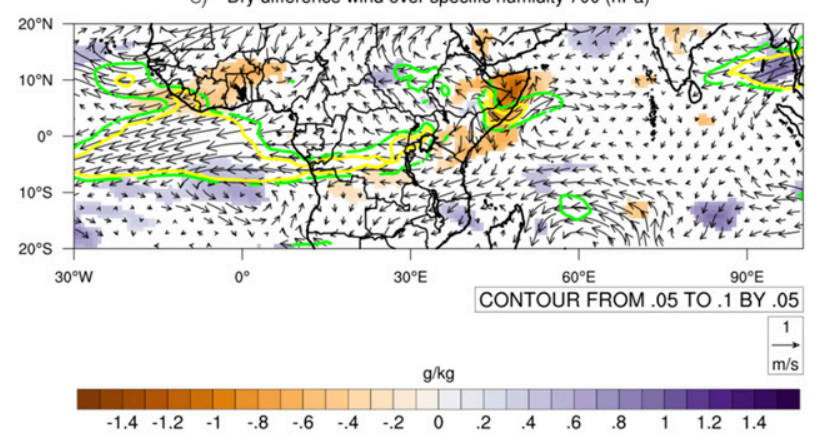

b) Mean moisture flux over MFC (1981-2019) $700(\mathrm{hPa})$

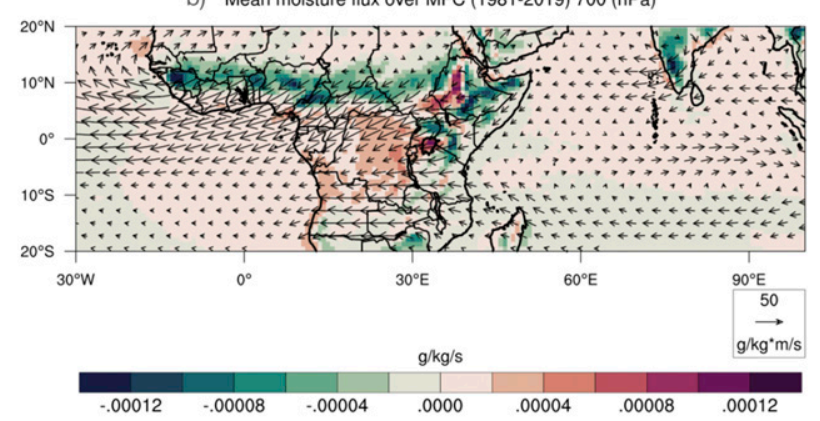

d) Wet difference moisture flux over MFC $700(\mathrm{hPa})$

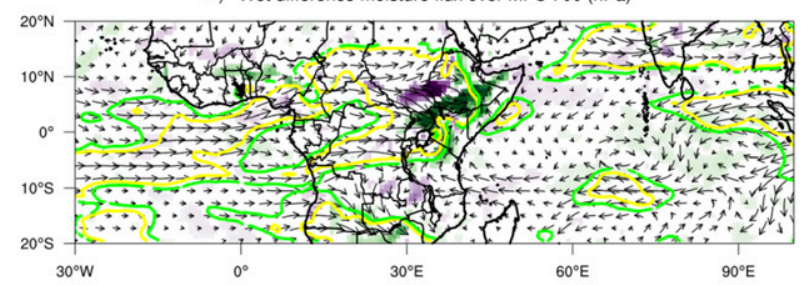

f) Dry difference moisture flux over MFC $700(\mathrm{hPa})$

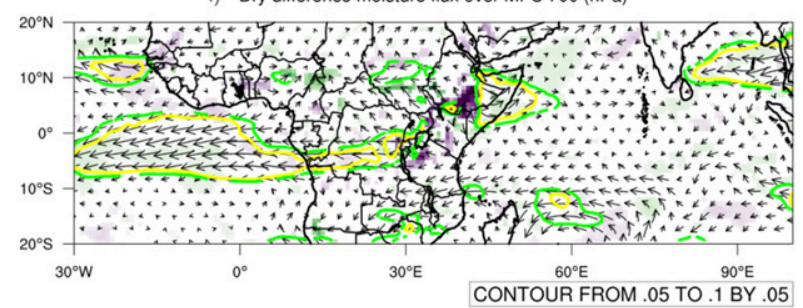

CONTOUR FROM .05 TO .1 BY 05

$\underset{\mathrm{g} / \mathrm{kg} * \mathrm{~m} / \mathrm{s}}{\stackrel{10}{\longrightarrow}}$

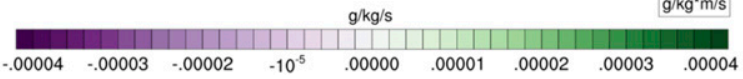

FIG. 9. Day-80-100 $700 \mathrm{hPa}$ averaged moisture flux and convergence. (a) Baseline winds ( $\mathrm{m} \mathrm{s}^{-1}$ ) over specific humidity (g kg ${ }^{-1}$ ) and (b) moisture flux $\left(\mathrm{g} \mathrm{kg} \mathrm{m} \mathrm{s}^{-1}\right.$ ) over moisture flux convergence $\left(\mathrm{g} \mathrm{kg} \mathrm{s}^{-1}\right)$. Wet and dry composite differences of (c), (e) winds over moisture and (d),(f) moisture flux over moist flux convergence, respectively. Moisture and moisture flux convergence are masked for $p<0.1$, and green and yellow contours indicate $p=0.1$ and $p=0.05$ for wind and moisture flux vectors, respectively.

associated in part with ascent over the Congo Basin (Figs. 10b,c). In the baseline of velocity potential there is a gradient through the Indian Ocean, and the positioning of the transition between ascent and descent may be an important factor for numerical models to realistically reproduce rainfall, and also future changes in rainfall. Figures $10 \mathrm{e}$ and $10 \mathrm{f}$ highlight the importance of the margin; when rainfall changes are largest there is a substantial change in western and central Indian Ocean equatorial velocity
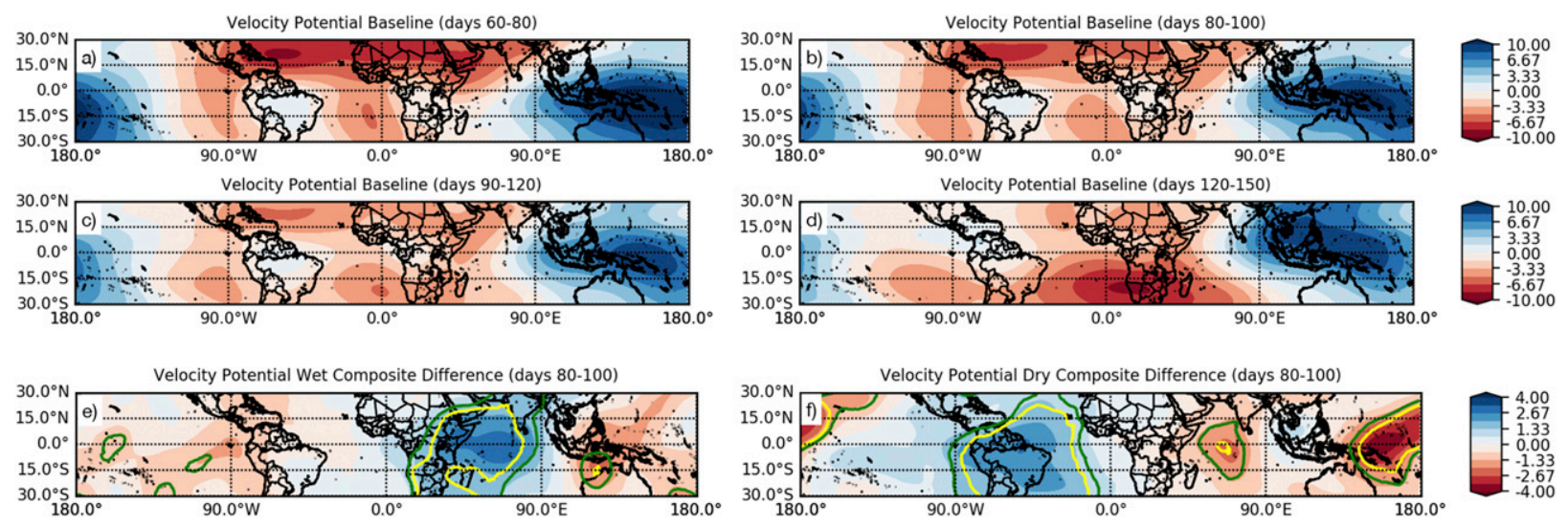

FIG. 10. (a) Day-60-80, (b) day-80-100, (c) day-90-120, and (d) day-120-150 subseasonal baseline velocity potential ( $\mathrm{m}^{2} \mathrm{~s}^{-1}$ ) at $200 \mathrm{hPa}$, and (e) wet and (f) dry composite difference velocity potential for days 80-100 with $p=0.1$ (green) and $p=0.05$ (yellow) contours indicating composite difference significance. All values are scaled by $10^{6}$. 
a) $200 \mathrm{hPa}$ Velocity Potential $\left(\mathrm{m}^{2} / \mathrm{s}\right)$ (days 60-80)

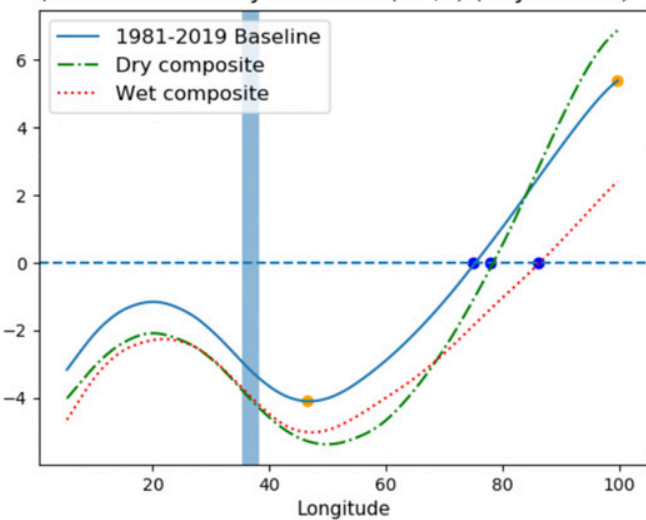

c) $200 \mathrm{hPa}$ Velocity Potential $\left(\mathrm{m}^{2} / \mathrm{s}\right)$ (days 90-120)

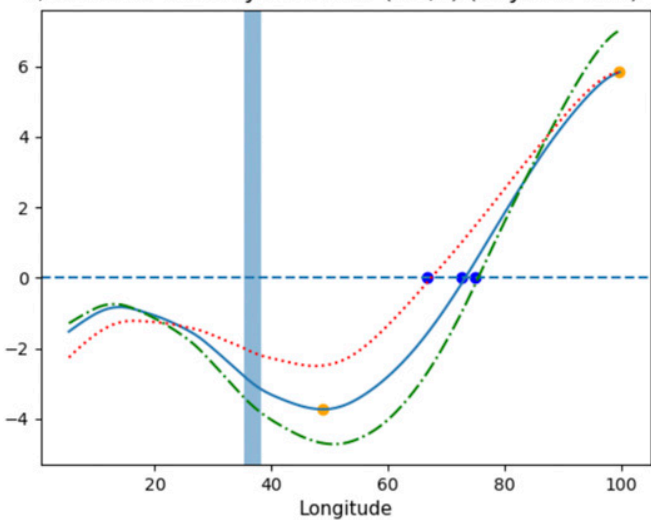

b) $200 \mathrm{hPa}$ Velocity Potential $\left(\mathrm{m}^{2} / \mathrm{s}\right)$ (days $\left.80-100\right)$

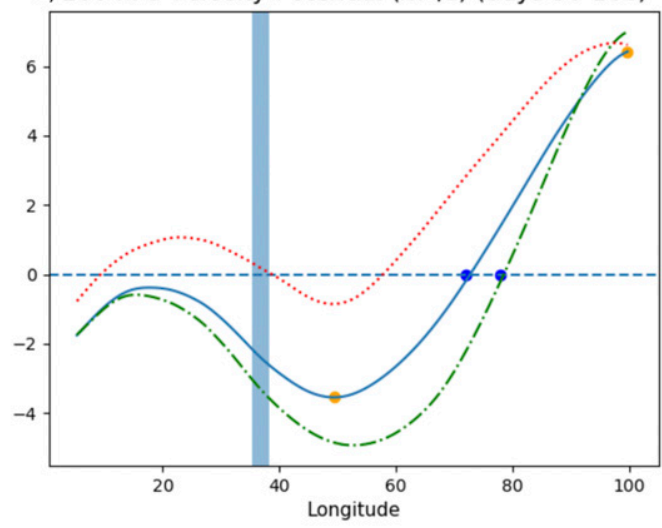

d) $200 \mathrm{hPa}$ Velocity Potential $\left(\mathrm{m}^{2} / \mathrm{s}\right)$ (days 120-150)

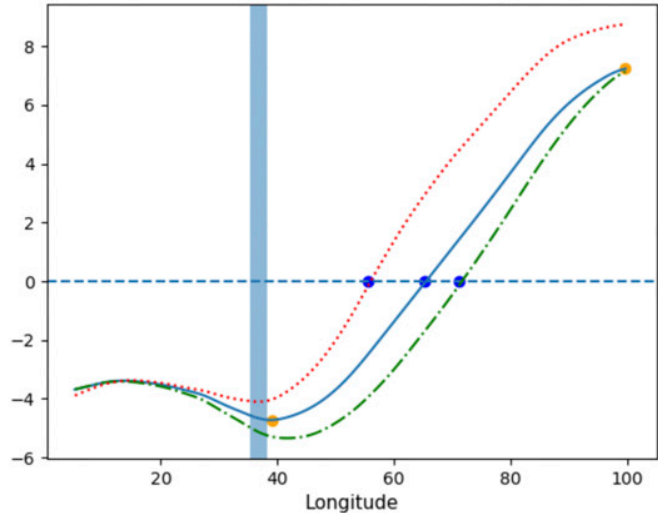

FIG. 11. (a) Day-60-80, (b) day-80-100, (c) day-90-120, and (d) day-120-150 longitudinal gradients in $200 \mathrm{hPa}$ velocity potential $\left(\mathrm{m}^{2} \mathrm{~s}^{-1}\right)$ over Africa and the Indian Ocean for subseasonal periods. Blue overlay indicates Kenyan longitudes. Blue points indicate the shifting zero point in the gradient in the baseline and composite velocity potentials. Yellow points indicate the maximum and minimum velocity potential points in the domain. Hovmöller diagrams are averaged from $10^{\circ} \mathrm{S}$ to $10^{\circ} \mathrm{N}$. All values are scaled by $10^{6}$.

potential, effectively shifting the longitudinal dipole that is apparent in Figs. 10a-d.

We have simplified the representation of this gradient in Fig. 11 for the baseline average and composite averages. Kenya sits close to a local minimum in velocity potential for most of the season. Figure 11 also shows that the change in composite average velocity potential is not just an intensification of the existing dipole, but also a shift in the location of the transition point with longitude. Aside from the day-60-80 period, there is an eastward shift in the dry composite and a westward shift in the wet composite. The longitude of where velocity potential changes sign in the Indian Ocean captures the shifting dipole between the warm pool ascent region and the African-Atlantic descent region. The magnitude of the local potential velocity maxima in the latitudinal gradient captures the strength of capping descent over Kenya.

The changes in velocity potential in wet composites (Fig. 12b) have a distinct traveling wave pattern and periodicity (a dominant mode of 45 days) that is reminiscent of the change that would be expected due to the Madden-Julian oscillation (MJO). The dry composite changes (Fig. 12c) are different in that there is a clearer zonal dipole, and although there is still a dominant mode with a similar period, the amplitude is smaller and there is a secondary mode with a shorter period that results in a diluted traveling wave pattern. There is an increase in descent over Africa and the western Indian Ocean at the start of the season that shifts to being an increase in western Indian Ocean descent through the rest of the season. The changes in Indian Ocean velocity potential are associated with ascent anomalies in the eastern Pacific and South America.

The mean wet composites (Fig. 12d) have an amplification of baseline periodicity with the important distinction that there is a period of ascent starting around day 80 . In the dry composites (Fig. 12e) there is less variation in the descent over Kenya with a consistent zonal overturning patter and persistent descent through the season, with the strongest descent over Kenya occurring at the onset of the rainy season.

The changes in large-scale vertical motions are connected to horizontal winds closer to the surface. The changes in day-80100 velocity potential (Figs. 10e,f) align with the change in midtropospheric easterly winds and moisture flux (Figs. 9c,e), with an increase in descent driving divergence at lower levels.

\section{a. Competing factors: Two dry years}

The year 1983 is a dry year that is characterized by an increase in descent over the Indian Ocean and eastern Africa. 

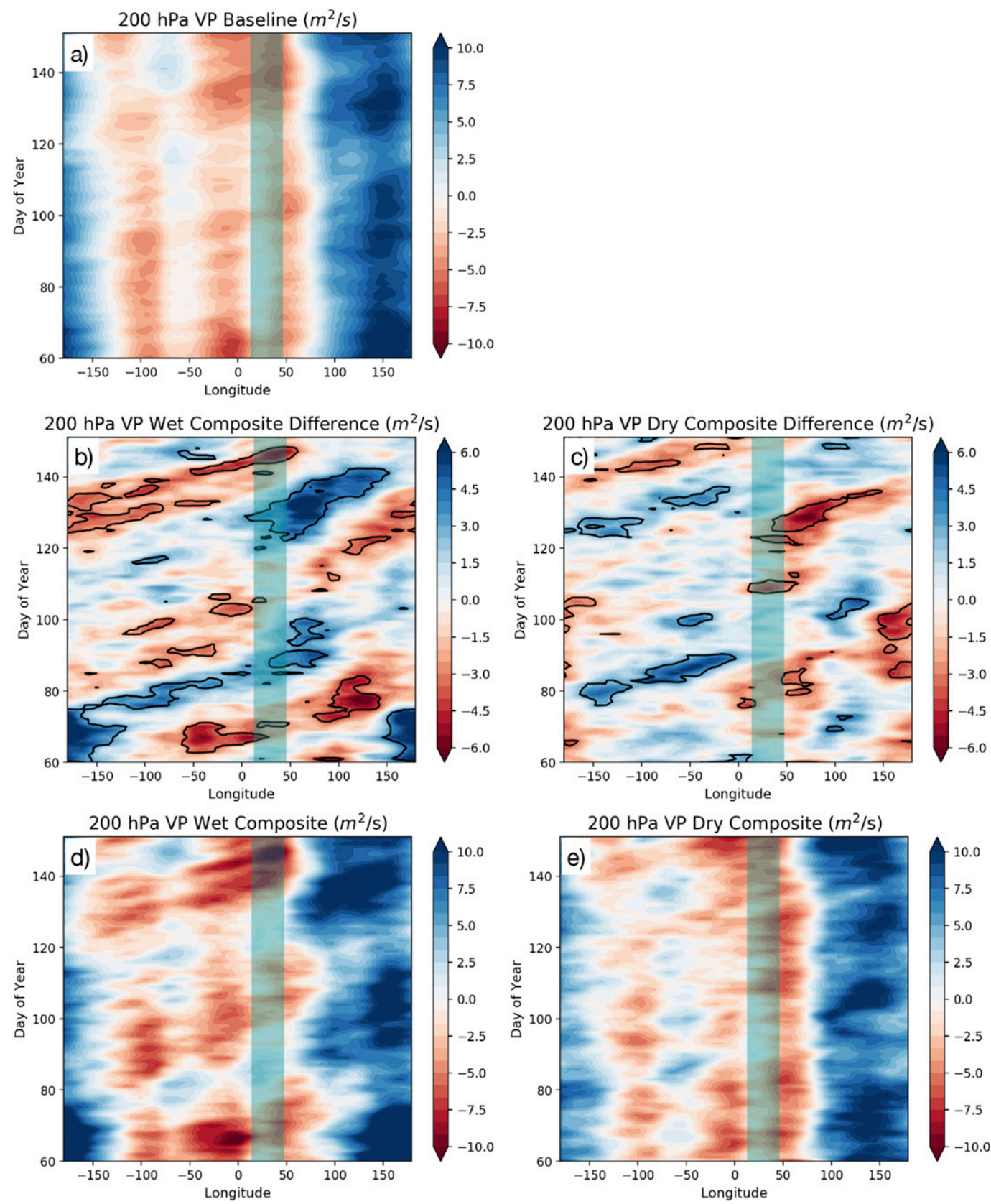

FIG. 12. Daily Hovmöller diagrams of tropical $200 \mathrm{hPa}$ (a) velocity potential $\left(\mathrm{m}^{2} \mathrm{~s}^{-1}\right)$ baseline, (b) wet composite difference, (c) dry composite difference, (d) wet composite average, and (e) dry composite average. The green overlay indicates approximate Kenyan longitudes. Hovmöller diagrams are averaged from $10^{\circ} \mathrm{S}$ to $10^{\circ} \mathrm{N}$. All values are scaled by $10^{6}$. Black contours indicate composite difference significance of $p<0.05$.

Although there is a warm western Indian Ocean SST anomaly at the beginning of the season (days 60-80) this does not last and is replaced by a cool anomaly by days $80-100$. The resulting MSE anomaly is a decrease in the midtroposphere; the moist component has a large decrease in the midtroposphere, while the dry component is increased throughout the column. The midtropospheric zonal anomaly that accompanies the change in large-scale overturning is easterly, concurrent with an increase in moist flux divergence from the surface into the midtroposphere.

Conversely, although 1984 is also a dry year, there is a decrease in the descent above East Africa (the same is true for 2009). The western Indian Ocean anomaly is cool, and there is less MSE (both wet and dry) in the midtroposphere. Midtropospheric zonal easterlies are also stronger during the day- $80-100$ period, accompanied by an increase in moist flux divergence. So, although 

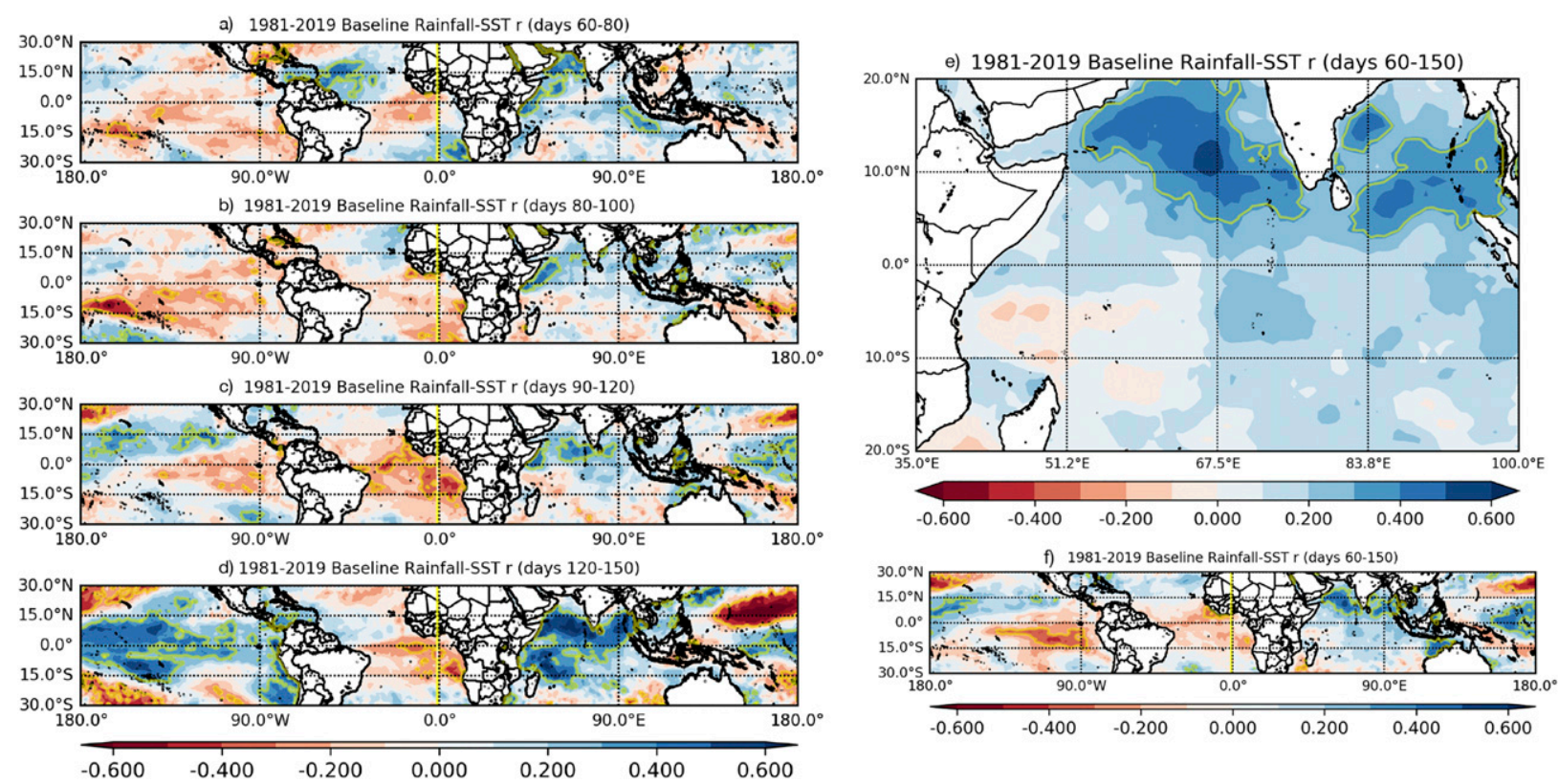

FIG. 13. (a) Day-60-80, (b) day-80-100, (c) day-90-120, and (d) day-120-150 subseasonal correlations ( $r$ ) between masked Kenyan rainfall from CHIRPS and tropical ERA-Interim SSTs. Seasonal (e) Indian Ocean and (f) tropical correlations. Yellow contours show areas where correlations are significant with $p<0.05$.

large-scale descent is weaker there is less rainfall. The largest ascent anomaly is over the Atlantic Ocean, rather than the Indian Ocean in agreement with midtropospheric zonal wind changes. Therefore, simply lifting the descending cap over Kenya is not enough to change rainfall.

There is also some variability in the wet years large-scale response. In two years (2010 and 2018) there is an increase in descent over East Africa, but this is small compared to the increase in descent over the Indian Ocean, pointing to a similar mechanism as the two dry years with anomalous ascent over the Atlantic. These cases highlight that the wet and dry changes are not always symmetrical in nature, but also that local and large-scale features must be considered simultaneously.

\section{b. Subseasonal correlations with global SSTS}

Although atmospheric diagnostics are the focus of this study, the correlation between Kenyan rainfall and tropical SSTs, shown in Fig. 13, is helpful context for understanding largescale circulation patterns, and local atmospheric dynamics. There are positive correlations with Indian Ocean SSTs off the coast of East Africa at the beginning of the season and strong positive correlations throughout the basin at the end of the season. During the peak of the rainy season (days 90-120) there are weak positive correlations in the northern Indian Ocean. These patterns are not reminiscent of Indian Ocean dipole (IOD) variability, which is not surprising as, like ENSO, the IOD tends to be strongest outside of the March-May period (Fan et al. 2016; Saji et al. 1999).

Although Indian Ocean SSTs, even at the western edge (Fan et al. 2016), are strongly affected by Pacific SSTs they can have their own distinct biases in modeled historical climate and future projections ( $\mathrm{Li}$ et al. 2016). The influence of a warming positive IOD-like bias would have a strong influence on Kenyan climate through a shift in lower-tropospheric winds and atmospheric moisture and a set of atmospheric diagnostics can help interpret the influence of such a biased pattern in the historical climate.

The subseasonal period with the highest rain rates (days 90-120) has significant correlations with the Atlantic Ocean, in particular the southern Atlantic. This pattern is apparent in days 80-100 and 120-150, although at the end of season negative correlations extend to the equator. Cooler SSTs are correlated with higher Kenyan rain rates except at the very beginning of the season. Equatorial Atlantic SSTs tend to be negatively correlated with $700 \mathrm{hPa}$ zonal winds through central Africa (not shown), and the significant negative correlation between rainfall and these SSTs reinforces the importance of this circulation on Kenyan rainfall. Atlantic SSTs are also known to be biased in coupled GCMs (Exarchou et al. 2018) and such biases may be reflected in zonal wind biases.

Finally, Figs. 13e and 13f show the seasonal correlations in the Indian Ocean and the global tropics, for comparison with the subseasonal correlations. The seasonal correlations highlight the central and eastern Pacific, and the northern Indian Ocean as having significant negative correlations. The positive correlations with the Indian Ocean along the coast of East Africa are lost, as are the strong negative correlations with Atlantic SSTs. As we have shown that changes in seasonal rainfall are influenced by local SSTs and their impact on moisture and divergence, and cross-continental flows, the information gained by examining the long-rains season at the subseasonal level can contribute to a better set of atmospheric diagnostics and understanding of seasonal variability. 
TABLE 1. Detrended correlations between masked Kenyan rainfall and atmospheric diagnostics for subseasonal averaged periods. Correlations are shown where $p<0.05$. There is zero time lag for all correlations.

\begin{tabular}{|c|c|c|c|c|c|}
\hline Diagnostic & $60-80$ & $80-100$ & $90-120$ & $120-150$ & $60-150$ \\
\hline $\begin{array}{l}\text { Near-surface East African zonal wind } \\
(925 \mathrm{hPa})^{\mathrm{a}}\end{array}$ & 0.82 & 0.74 & 0.67 & 0.39 & 0.79 \\
\hline Central African zonal wind $(700 \mathrm{hPa})^{\mathrm{b}}$ & 0.58 & 0.77 & 0.59 & 0.35 & 0.58 \\
\hline Local vertical velocity $(400-700 \mathrm{hPa})^{\mathrm{c}}$ & -0.87 & -0.85 & -0.76 & -0.68 & -0.70 \\
\hline Midtropospheric MSE $(500-700 \mathrm{hPa})^{\mathrm{c}}$ & 0.51 & 0.54 & 0.66 & 0.69 & 0.53 \\
\hline Near-surface MSE $(925-1000 \mathrm{hPa})^{\mathrm{c}}$ & 0.61 & - & 0.39 & 0.62 & 0.40 \\
\hline Local MFC $(600-850 \mathrm{hPa})^{\mathrm{c}}$ & 0.66 & 0.70 & 0.65 & 0.51 & 0.65 \\
\hline Velocity potential zero-point location ${ }^{\mathrm{d}}$ & -0.32 & -0.57 & -0.36 & - & -0.47 \\
\hline Velocity potential maximum ${ }^{\mathrm{e}}$ & 0.35 & 0.54 & 0.45 & 0.52 & 0.47 \\
\hline
\end{tabular}

${ }^{\text {a }}$ Average over $5^{\circ} \mathrm{S}-5^{\circ} \mathrm{N}, 30^{\circ}-45^{\circ} \mathrm{E}$.

${ }^{\mathrm{b}}$ Average over $10^{\circ} \mathrm{S}-5^{\circ} \mathrm{N}, 10^{\circ}-30^{\circ} \mathrm{E}$.

${ }^{c}$ Average over $4^{\circ} \mathrm{S}-4^{\circ} \mathrm{N}, 33^{\circ}-42^{\circ} \mathrm{E}$.

${ }^{\mathrm{d}}$ Longitude of transition from positive to negative between $0^{\circ}$ and $100^{\circ} \mathrm{E}\left(10^{\circ} \mathrm{S}-10^{\circ} \mathrm{N}\right.$ average $)$.

${ }^{\mathrm{e}}$ Magnitude of local maxima between $20^{\circ} \mathrm{S}$ and $20^{\circ} \mathrm{N}\left(33^{\circ}-42^{\circ} \mathrm{E}\right.$ average).

\section{Discussion: Subseasonal diagnostics}

Table 1 contains a summary of the atmospheric diagnostics that we propose for use in evaluating models for the Kenyan long-rains season. The relationship between the diagnostics and Kenyan rainfall has been studied for our subseasonal aggregation periods and for the seasonal average to see how these diagnostics perform against the full baseline of long-rains seasons. Zonal winds near the surface and in the midtroposphere are correlated with onset and main rainy season periods, although the surface winds are more highly correlated at the beginning of the season while midtropospheric winds have the highest correlations in the day- $80-100$ period pointing to increased rainfall associated with anomalous westerlies.

Variables that are highly correlated with rainfall throughout the season are, unsurprisingly, the local variables associated with moisture and stability (MFC, MSE, strength of ascent). Apart from the early onset period of day-60-80 midtropospheric MSE (not saturated) is more strongly correlated with rainfall rather than surface MSE. To assess whether this is simply a result of increased local vertical moisture flux and is predominantly influenced by, rather than influencing, precipitation, we applied a series of time lags to the aggregation periods for rainfall relative to MSE. For time lags between 0 and 20 days, midtropospheric MSE had higher correlations than all other metrics, except for local vertical velocity at a 5 day lag, for days 90-120 ( $r=0.52, p<0.05$, with precipitation at a 20 day lag). This indicates that higher rainfall is not necessarily the preceding factor, and the importance of moisture in the midtroposphere for rainfall, warranting further investigation.

We have used the dipole transition longitude of $200 \mathrm{hPa}$ velocity potential in the Indian Ocean, and the strength of the meridional maxima as a diagnostic for the strength and location of large-scale ascent, as it relates to the seasonal latitudinal progression of large-scale ascent, and the warm pool region Walker overturning. The shifting of the margin, represented by the transition longitude, is most correlated with Kenyan rainfall for the day-80-100 period, an eastward shift in this point is associated with decreased rainfall. The velocity potential maximum is also most correlated during this period. Although the transition longitude is not correlated at the end of the season, the maximum is, indicating that the meridional shift is velocity potential is more important than the zonal shift at this point in the season.

\section{Conclusions}

In this study we investigated how very wet and dry MAM seasons deviate from the baseline climatology at a daily time step with a view to understanding the characteristics seasonal variability and to highlight useful subseasonal aggregation periods to understand this variability. We have shown that in very wet (dry) seasons most rainfall change occurs at the end of March and the beginning of April, in effect starting the rainy season early (late) and concentrating more (less) rainfall earlier in the season.

Using the daily climatology of the composite differences and these suggested aggregation periods, we were able to trace changes in the atmosphere from the local scale to the largescale overturning and variations in SSTs. In doing so we highlighted a number of atmospheric features that are important in driving rainfall variability.

These features include local ascent above $700 \mathrm{hPa}$, midtropospheric moisture flux convergence, moist static energy (latent heat) in the lower and midtroposphere, and the accompanying lower-tropospheric inflow of moisture to Kenya, and midtropospheric zonal winds over central Africa. These local features highlighted regional interactions and were linked to the large-scale circulation represented by $200 \mathrm{hPa}$ velocity potential variations, and subseasonal correlations with SST in the western Indian Ocean and equatorial Atlantic Ocean.

Two features that are particularly interesting are midtropospheric moisture, and $700 \mathrm{hPa}$ easterlies over central Africa. Column moisture is usually implicated in changes in stability of the atmosphere, as was done for Kenya by Yang et al. (2015a). However, we also found that moisture in the midtroposphere is strongly linked to Kenyan rainfall. Free-tropospheric moisture 
has been shown to be an important control on transition to deep convection (Sherwood 1999). The availability of moisture in East Africa is strongly tied to horizontal advection, and for midtropospheric moisture we argue that this is strongly influenced by the strength of easterlies over central Africa. The relationship between East Africa and moisture transport into the Congo Basin has been examined using a regional model by Cook and Vizy (2013), highlighting that this mechanism may be an important driver of future change for Kenyan rainfall. Maloney (2009) concluded that models must be able to realistically simulate the lower-tropospheric specific humidity and zonal winds to properly capture variability, and we would argue that this would be a very useful lens for model evaluation in Kenya.

\section{Implications for model evaluation}

Model representation of MAM trends in both historical and future simulations have been investigated by a number of studies (Rowell et al. 2015; Funk et al. 2008; Giannini et al. 2018), and a number of different large-scale teleconnections have been suggested as causes for the historical trends in East African MAM rainfall, including changes in the Walker circulation (Funk et al. 2014; Williams and Funk 2011) and variability of Pacific SSTs (Hoell and Funk 2014; Lyon 2014; Vigaud et al. 2017). Coupled GCMs do not simulate these teleconnections with East Africa in a realistic way, with trends in the atmosphere-only AMIP simulations being more realistic in the historical period.

There are also model biases in the mean MAM season that are larger in coupled than AMIP models. GCMs are unable to capture the baseline seasonality, with late MAM onset shown by Dunning et al. (2017) and some coupled models having OND as the wettest season rather than MAM, indicating that SST biases, or atmosphere-ocean feedback in coupled models are adding biases to those that already exist in AMIP simulations (Tierney et al. 2015).

It is because of these many biases and complex teleconnections that we examined the MAM season in Kenya at a variety of spatial scales and with new aggregation periods to highlight which features are associated with onset and maintenance, but also how key atmospheric processes are connected at different scales. While we highlighted midtropospheric moisture and central African easterlies as key features to investigate in models, biases can only be properly understood in the context of how they influence more local atmospheric conditions over Kenya and are influenced by biases in the large-scale circulation.

Applying this set of diagnostics to the full ensemble of contemporary and future CMIP simulations including atmosphere-only simulations is the logical next step. Region specific investigations of models has been suggested as key to understanding and improving model skill for Africa (James et al. 2018), and this is what we suggest doing with this diagnostic set for Kenya. Not only will this contribute to understanding the behavior of models, but it will also contribute to better communication of our confidence in their projections and the climate futures they predict.

Acknowledgments. This document is an output from the REACH Programme funded by U.K. Aid from the U.K.
Foreign, Commonwealth and Development Office (FCDO) for the benefit of developing countries (Programme Code 201880). However, the views expressed and information contained in it are not necessarily those of or endorsed by FCDO, which can accept no responsibility for such views or information or for any reliance placed on them. We thank the three anonymous reviewers for their critical reading of this manuscript and whose suggestions have improved and clarified this work.

\section{REFERENCES}

Boschat, G., I. Simmonds, A. Purich, A. Cowan, T. Pezza, and A Bernandes, 2016: On the use of composite analyses to form physical hypotheses: An example from heat wave-SST associations. Sci. Rep., 6, 29599, https://doi.org/10.1038/srep29599.

Camberlin, P., and R. E. Okoola, 2003: The onset and cessation of the "long rains" in eastern Africa and their interannual variability. Theor. Appl. Climatol., 54, 43-54, https://doi.org/ 10.1007/s00704-002-0721-5.

Cook, K. H., and E. K. Vizy, 2013: Projected changes in East African rainy seasons. J. Climate, 26, 5931-5948, https:// doi.org/10.1175/JCLI-D-12-00455.1.

Creese, A., and R. Washington, 2016: Using qflux to constrain modeled Congo Basin rainfall in the CMIP5 ensemble. J. Geophys. Res. Atmos., 121, 13 415-13 442, https://doi.org/ 10.1002/2016JD025596.

Dawson, A., 2016: Windspharm: A high-level library for global wind field computations using spherical harmonics. J. Open Res. Software, 4, e31, https://doi.org/10.5334/jors.129.

Dee, D. P., and Coauthors, 2011: The ERA-Interim reanalysis: Configuration and performance of the data assimilation system. Quart. J. Roy. Meteor. Soc., 137, 553-597, https://doi.org/ 10.1002/qj.828.

Derbyshire, S. H., I. Beau, P. Bechtold, J. Y. Grandpeix, J. M. Piriou, J. L. Redelsperger, and P. M. Soares, 2004: Sensitivity of moist convection to environmental humidity. Quart. J. Roy. Meteor. Soc., 130, 3055-3079, https://doi.org/10.1256/qj.03.130.

Dinku, T., C. Funk, P. Peterson, R. Maidment, T. Tadesse, H. Gadain, and P. Ceccato, 2018: Validation of the CHIRPS satellite rainfall estimates over eastern Africa. Quart. J. Roy. Meteor. Soc., 144, 292-312, https://doi.org/10.1002/qj.3244.

Dunning, C. M., R. P. Allan, and E. Black, 2017: Identification of deficiencies in seasonal rainfall simulated by CMIP5 climate models. Environ. Res. Lett., 12, 114001, https://doi.org/10.1088/ 1748-9326/aa869e.

Exarchou, E., C. Prodhomme, L. Brodeau, V. Guemas, and F. Doblas-Reyes, 2018: Origin of the warm eastern tropical Atlantic SST bias in a climate model. Climate Dyn., 51, 18191840, https://doi.org/10.1007/s00382-017-3984-3.

Fan, L., Q. Liu, C. Wang, and F. Guo, 2016: Indian Ocean dipole modes associated with different types of ENSO development. J. Climate, 30, 2233-2249, https://doi.org/10.1175/JCLI-D-16-0426.1.

Fiorino, M., 2004: A multi-decadal daily sea surface temperature and sea ice concentration data set for the ERA-40 reanalysis. ERA Tech. Rep. Series 12, 25 pp., https://www.ecmwf.int/en/ elibrary/9396-multi-decadal-daily-sea-surface-temperature-andsea-ice-concentration-data-set-era.

Funk, C., M. D. Dettinger, J. C. Michaelsen, J. P. Verdin, M. E. Brown, M. Barlow, and A. Hoell, 2008: Warming of the Indian Ocean threatens eastern and southern African food security but could be mitigated by agricultural development. Proc. Natl. Acad. Sci. USA, 105, 11081-11086, https://doi.org/ 10.1073/pnas.0708196105. 
—, A. Hoell, S. Shukla, I. Bladé, B. Liebmann, J. B. Roberts, F. R. Robertson, and G. Husak, 2014: Predicting East African spring droughts using Pacific and Indian Ocean sea surface temperature indices. Hydrol. Earth Syst. Sci., 18, 4965-4978, https://doi.org/10.5194/hess-18-4965-2014.

— , and Coauthors, 2015: The Climate Hazards Infrared Precipitation with Stations-A new environmental record for monitoring extremes. Sci. Data, 2, 150066, https://doi.org/10.1038/sdata.2015.66.

Giannini, A., B. Lyon, R. Seager, and N. Vigaud, 2018: Dynamical and thermodynamic elements of modeled climate change at the East African margin of convection. Geophys. Res. Lett., 45, 992-1000, https://doi.org/10.1002/2017GL075486.

Hirpa, F. A., E. Dyer, R. Hope, D. O. Olago, and S. J. Dadson, 2018: Finding sustainable water futures in data-sparse regions under climate change: Insights from the Turkwel River basin, Kenya. J. Hydrol. Reg. Stud., 19, 124-135, https://doi.org/ 10.1016/j.ejrh.2018.08.005.

Hoell, A., and C. Funk, 2014: Indo-Pacific sea surface temperature influences on failed consecutive rainy seasons over eastern Africa. Climate Dyn., 43, 1645-1660, https://doi.org/10.1007/ s00382-013-1991-6.

Holloway, C. E., and J. D. Neelin, 2009: Moisture vertical structure, column water vapor, and tropical deep convection. J. Atmos. Sci., 66, 1665-1683, https://doi.org/10.1175/2008JAS2806.1.

James, R., and Coauthors, 2018: Evaluating climate models with an African lens. Bull. Amer. Meteor. Soc., 99, 313-336, https:// doi.org/10.1175/BAMS-D-16-0090.1.

Kinuthia, J. H., 1992: Horizontal and vertical structure of the Lake Turkana jet. J. Appl. Meteor., 31, 1248-1274, https://doi.org/ 10.1175/1520-0450(1992)031<1248:HAVSOT>2.0.CO;2.

Kjellsson, J., 2015: Weakening of the global atmospheric circulation with global warming. Climate Dyn., 45, 975-988, https:// doi.org/10.1007/s00382-014-2337-8.

Li, G., S.-P. Xie, and Y. Du, 2016: A robust but spurious pattern of climate change in model projections over the tropical Indian Ocean. J. Climate, 29, 5589-5608, https://doi.org/10.1175/ JCLI-D-15-0565.1.

Lyon, B., 2014: Seasonal drought in the Greater Horn of Africa and its recent increase during the March-May long rains. J. Climate, 27, 7953-7975, https://doi.org/10.1175/JCLI-D-13-00459.1.

MacLeod, D., 2018: Seasonal predictability of onset and cessation of the East African rains. Wea. Climate Extremes, 21, 27-35, https://doi.org/10.1016/j.wace.2018.05.003.

Maloney, E. D., 2009: The moist static energy budget of a composite tropical intraseasonal oscillation in a climate model. J. Climate, 22, 711-729, https://doi.org/10.1175/2008JCLI2542.1.

Niang, I., and Coauthors, 2014: Africa. Climate Change 2014: Impacts, Adaptation, and Vulnerability, Part B: Regional Aspects, V. R. Barros et al., Eds., Cambridge University Press, 1199-1266, https://doi.org/10.1017/CBO9781107415386.002.

Nicholson, S., 2016: The Turkana low-level jet: Mean climatology and association with regional aridity. Int. J. Climatol., 36, 2598-2614, https://doi.org/10.1002/joc.4515.

_ 2017: Climate and climatic variability of rainfall over eastern Africa. Rev. Geophys., 55, 590-635, https://doi.org/10.1002/ 2016RG000544.
REACH, 2015: Country Diagnostic Report, Kenya. REACH Working Paper 3, 24 pp., https://reachwater.org.uk/wp-content/ uploads/2015/12/CDR-Kenya-WEB.pdf.

Rowell, D. P., B. B. B. Booth, S. E. Nicholson, and P. Good, 2015: Reconciling past and future rainfall trends over East Africa. J. Climate, 28, 9768-9788, https://doi.org/10.1175/JCLI-D-150140.1 .

Saji, N. H., B. N. Goswami, P. N. Vinayachandran, and T. Yamagata, 1999: A dipole mode in the tropical Indian Ocean. Nature, 401, 360-363, https://doi.org/10.1038/43854.

Sherwood, S. C., 1999: Convective precursors and predictability in the tropical western Pacific. Mon. Wea. Rev., 127, 29772991, https://doi.org/10.1175/1520-0493(1999)127<2977:CPAPIT> 2.0.CO;2.

Tanaka, H. L., N. Ishizaki, and A. Kitoh, 2004: Trend and interannual variability of Walker, monsoon and Hadley circulations defined by velocity potential in the upper troposphere. Tellus, 56A, 250-269, https://doi.org/10.1111/j.1600-0870.2004.00049.x.

Terray, P., P. Delecluse, S. Labattu, and L. Terray, 2003: Sea surface temperature associations with the late Indian summer monsoon. Climate Dyn., 21, 593-618, https://doi.org/10.1007/ s00382-003-0354-0.

Tierney, J. E., C. C. Ummenhofer, and P. B. DeMenocal, 2015: Past and future rainfall in the Horn of Africa. Sci. Adv., 1, e1500682, https://doi.org/10.1126/sciadv.1500682.

Vellinga, M., and S. Milton, 2018: Drivers of interannual variability of the East African "Long Rains." Quart. J. Roy. Meteor. Soc., 144, 861-876, https://doi.org/10.1002/qj.3263.

Vigaud, N., B. Lyon, and A. Giannini, 2017: Sub-seasonal teleconnections between convection over the Indian Ocean, the East African long rains and tropical Pacific surface temperatures. Int. J. Climatol., 37, 1167-1180, https://doi.org/10.1002/joc.4765.

Washington, R., R. James, H. Pearce, W. M. Pokam, and W. Moufouma-Okia, 2013: Congo Basin rainfall climatology: Can we believe the climate models? Philos. Trans. Roy. Soc. London, 368B, 20120296, https://doi.org/10.1098/rstb.2012.0296.

Webster, P. J., and S. Young, 1992: Monsoon and ENSO: Selectively iterative systems. Quart. J. Roy. Meteor. Soc., 118, 877-926, https://doi.org/10.1002/qj.49711850705.

Williams, A. P., and C. Funk, 2011: A westward extension of the warm pool leads to a westward extension of the Walker circulation, drying eastern Africa. Climate Dyn., 37, 2417-2435, https://doi.org/10.1007/s00382-010-0984-y.

World Health Organization, 2017: Safely managed drinking water. WHO Tech. Rep., 56 pp., https://www.who.int/water_sanitation_ health/publications/safely-managed-drinking-water/en/.

Yang, W., R. Seager, M. A. Cane, and B. Lyon, 2015a: The annual cycle of East African precipitation. J. Climate, 28, 2385-2404, https://doi.org/10.1175/JCLI-D-14-00484.1.

$-, \ldots, \ldots$, and $\longrightarrow, 2015 \mathrm{~b}$ : The rainfall annual cycle bias over East Africa in CMIP5 coupled climate models. J. Climate, 28, 9789-9802, https://doi.org/10.1175/JCLI-D-15-0323.1.

Zorita, E., and F. F. Tilya, 2002: Rainfall variability in northern Tanzania in the March-May season (long rains) and its links to large-scale climate forcing. Climate Res., 20, 31-40, https:// doi.org/10.3354/cr020031. 